\title{
LAS MARCAS DEL PROCESO ORAL Y ESCRITO DISENAADO EN EL PROYECTO DE NUEVO CPC CHILENO $^{* * *}$
}

\section{THE ORAL AND WRITTEN PROCESS HIGHLIGHTS DESIGNED IN THE NEW CHILEAN CPC DRAFT BILL}

\section{Diego I. PALOMO VÉLEZ ${ }^{* * *}$}

\begin{abstract}
RESUMEN: El artículo se hace cargo de un análisis de la decisión de introducir mayores grados de oralidad en un futuro nuevo proceso civil. Con este propósito se contextualiza el proceso de reforma procesal civil, se revisa la situación actual, dominada por el monopolio de la escritura y sus consecuencias, y se termina con una valoración de las directrices que en cuanto al tema de la oralidad se contienen en el Proyecto de Nuevo CPC chileno.
\end{abstract}

Palabras clave: oralidad, proceso por audiencias, proyecto de CPC.

ABSTRACT: This article involves an analysis of the decision to introduce higher levels of orality in a future civil procedure. It is with this purpose that the process of civil procedure reform is contextualized, the current situation dominated by the monopoly of the writing and its consequences is revised, and it is concluded with an evaluation of the guidelines about oral theme that are contained in the new Chilean CPC draft bill.

Key words: orality, processes by hearings, new chilean CPC draft bill.

\section{A MODO DE INTRODUCCIÓN: EL PROCESO DE REFORMAS PROCESALES, LA ORALIDAD Y SU LLEGADA A LA JUSTICIA CIVIL}

El proceso de modernización del sistema procesal solo tuvo su comienzo con la aprobación e implementación de la reforma al modelo procesal penal. De hecho, en rigor, este suceso no puede ser entendido sino como el punto de partida de la reforma integral de un sistema procesal cuyas dificultades exigían afrontar su modificación general. En efecto, a la reforma procesal penal han seguido otras que han buscado expandir a otros ámbitos algunas de las virtudes encontradas a propósito de aquella

\footnotetext{
* Este trabajo es parte de proyecto Fondecyt $\mathrm{N}^{\circ} 1085321$ titulado "La oralidad en el marco de los cambios que requiere el sistema procesal civil. Sus efectos en la reforma a la justicia civil chilena" (2008-2009), del que quien escribe es director responsable.

${ }_{* *}^{*}$ En octubre del año pasado, nuestro más importante procesalista, el profesor Raúl Tavolari Oliveros, fue nombrado Presidente del Instituto Iberoamericano de Derecho Procesal en el marco de las XXI Jornadas Iberoamericanas realizadas en Lima. El procesalismo chileno se encuentra muy complacido por el reconocimiento efectuado a quien constituye su principal representante. Este trabajo está dedicado a él.

${ }^{* * *}$ Licenciado en Ciencias Jurídicas y Sociales, Universidad de Talca. Doctor en Derecho, Universidad Complutense de Madrid, Profesor asociado de la Universidad de Talca. Correo electrónico: dpalomo@utalca.cl
} 
que por vez primera en Chile apostó seriamente por el predominio de la oralidad como forma del procedimiento.

Sabido es que estas, que siguieron la línea del predominio de la oralidad, no han tenido un buen inicio y no han tardado en experimentar dificultades de diversa naturaleza y entidad, fundamentalmente (no únicamente), de implementación orgánica ya que los cambios procedimentales aprobados no se acompañaron de la inversión en recursos adecuados para afrontarlas. Se han adoptado correctivos a posteriori.

Nos referimos a la denominada nueva Justicia de familia y laboral, la primera en plena fase de adecuación o perfeccionamiento a la luz de los problemas de funcionamiento que la práctica de la misma ha ido evidenciando ${ }^{1}$, y la reforma procesal laboral ya presente en la Región Metropolitana, tras una puesta en marcha inicial que debió ser suspendida para afrontar de mejor modo su esperada entrada en vigencia, evitando repetir los errores cometidos a propósito de la reforma a los tribunales de familia.

¿Qué ha sucedido con la reforma procesal civil? Se trata -nuevamente- de una tarea de gran envergadura, que debe superar los esfuerzos desplegados en las reformas precedentes. El trabajo en torno a ella ha debido convivir con el "salvataje" de la reforma a la Justicia de familia y la puesta en marcha de la reforma a la Justicia laboral; en gran medida, se ha preferido -de momento- intentar consolidar las reformas procesales aprobadas, para luego asumir la labor de la reforma del modelo procesal civil ${ }^{2}$.

Sin embargo, ya desde hace algunos años, gracias a las actividades de discusión y trabajos desarrollados por académicos nacionales y las aportaciones de ilustres profesores extranjeros, se viene instando por la conveniencia y hasta la necesidad de introducir cambios en el modelo vigente que se ve como el más deficiente en su funcionamiento. Está ya instalada la idea de que es necesario también avanzar en la mejora de un modelo procesal civil que, en cuanto la sociedad actual fue tornándose más compleja (y los

\footnotetext{
${ }^{1}$ La Ley No 20.286 introduce mejoras orgánicas y procedimentales a los Juzgados de Familia en todo el país, lo que -se espera- permitirá iniciar un amplio proceso de estabilización y normalización del sistema vigente desde el 1 octubre de 2005. Quien desee revisar desde un punto de vista más empírico el funcionamiento de la "oralidad" en los Tribunales de Familia puede revisar un informe en el cual se recogen logros y dificultades experimentados con la reforma a la Justicia de Familia, especialmente desde la perspectiva del cumplimiento de la oralidad y sus reglas conexas, léase inmediación, concentración y publicidad. Véase: SiLVA, J. y otros "Estudio exploratorio sobre el funcionamiento de la oralidad en los Tribunales de Familia en la Región Metropolitana", en: CABEZÓN (2008).

2 A no todos les parece normal este proceder. Comentando las reformas España, han sentenciado: "Con olvido de Sócrates, de Platón y de Aristóteles, no pocos piensan (o actúan como si pensaran) que a base de leyes se puede lograr la felicidad de las naciones y de los hombres todos. Grave, gravisimo error. ;Pobre sociedad, pobre Nación aquélla en las que sus dirigentes están enfermos de incontinencia legislativa y en la que las leyes parecen aprobarse, no para ser cumplidas, sino para ser reformadas! ;Pobre pais aquél en que se aprueban nuevas leyes para anotarse 'tantos' politicos; en que, a falta o en vez de inangurar puertos o carreteras nuevas, se inauguran leyes nuevas, a veces, demasiadas veces, precipitadas y, por tanto, inefectivas y dañinas! DE LA OLIVA (2008): Casación, oralidad y nuevo proceso civil: tres conferencias chilenas. (Santiago, Ed. Jurídica de Santiago) 93 pp. Este libro recoge las conferencias dictadas por el profesor en el Seminario "Recurso de casación: presente y futuro", realizado en la Facultad de Derecho de la Pontificia Universidad Católica de Chile los días 20 y 21 de octubre de 2008. Esta afirmación la realizó en el marco de su conferencia "Algunas ideas para la formulación de un modelo de casación civil".
} 
niveles de litigiosidad aumentaron $)^{3}$, no ha tardado en evidenciar importantes problemas $^{4}$. Creo que no carecemos de razón aquellos que hemos sostenido (utilizando una expresión futbolística, pero suficientemente ilustrativa) que dentro del sistema procesal chileno existen modelos procesales que están jugando en la "primera división", mientras que otros (el modelo procesal civil), siguen jugando en los "potreros".

Siguiendo la línea trazada por las reformas procesales locales precedentes y las reformas realizadas en otros países (España, Alemania y Uruguay por citar algunos casos $)^{5}$, los trabajos en torno a la reforma procesal civil también se sostienen en la introducción de la oralidad en los procesos. Como bien se ha dicho acertadamente por Martin ${ }^{6}$, hoy en día, ante la aparición de cualquier reforma procesal de envergadura, una de las cuestiones que centra los focos de atención en sus momentos iniciales es la determinación de si el producto legislativo se encuadrará dentro de los procesos orales, o bien, por el contrario, responderá más a un modelo escrito. Claro está que la opción por una u otra forma procedimental debe venir determinada por el respectivo aporte a la eficiencia de las actuaciones procesales.

Pues bien, los problemas principales que exhibe el actual modelo y a los que se debiera hacer frente a través de la reforma son dos, convertidos ellos en factores protagonistas de la preocupante falta de eficiencia del mismo. Primero, el problema de la lentitud que se aprecia en la respuesta que reciben los justiciables, en otras palabras, el alto nivel de dilación que presenta nuestra Justicia civil ${ }^{7}$. Que el proceso civil objeto de este trabajo sea, como ha apuntado un destacado procesalista ${ }^{8}$, un proceso de "dinero" (un proceso dispositivo), no puede justificar esta situación.

El segundo gran problema que presenta el modelo, también desde la perspectiva de la eficiencia, es que el fondo y la calidad de la decisión (nos valemos aquí de los

\footnotetext{
${ }^{3}$ Un reciente informe muestra a Chile como uno de los países de la región que reportó un mayor índice de litigiosidad civil. VARGAS (2007).

${ }^{4}$ Para una visión nacional y comparada sobre el tema en Chile, véase: DE LA Oliva y PALOMO VÉLEZ (2007).

5 Con ocasión de haber participado del Primer Congreso Internacional de Derecho Procesal Civil realizado en Nicaragua entre el 26 y el 28 de noviembre de 2008, invitado en calidad de conferencista por la Corte Suprema de dicho país, pude constatar que la opción por el predominio de la oralidad en la nueva Justicia civil es un desafío que también están asumiendo los nicaragüenses. Frente a problemas similares a los nuestros, se está apostando por una solución similar. Para mayores detalles véase: MARTíNEZ (2008). Esta edición especial recoge una serie de trabajos que describen las líneas fundamentales de la reforma procesal civil que se propone para dicho país.

${ }^{6}$ MARTín (2008).

7 Bien se ha señalado que el sistema procesal civil chileno vive una de sus más profundas crisis en los últimos cien años, lo que se refleja en su profunda lentitud que se traduce en que en las causas más complejas se puede alcanzar una duración superior a los diez años y que la gran mayoría de las que se tramitan en un juicio ordinario no terminen, si se interpone el recurso extraordinario de casación, antes de los cinco años en la Región Metropolitana, donde se concentra la mayoría de los asuntos: NúÑEZ OJEDA (2005). Un diagnóstico levantado sobre la base de entrevistas y encuestas realizadas a usuarios, jueces, secretarios, funcionarios y abogados véase en: GUTIÉRREZ y MALDONADO (2006).

${ }^{8}$ Estamos aludiendo al profesor Juan Montero Aroca, catedrático de la Universidad de Valencia.
} 
criterios que ha utilizado recientemente Taruffo $)^{9}$ van perdiendo relevancia en el esquema formal que impone el actual sistema, que apareja -entre otras consecuencias- la virtual invisibilidad del juez durante todo el proceso. Esta pérdida de relevancia del fondo no puede ser de otro modo en un modelo en el cual quien debe decidir el conflicto suele no tener contacto directo con las partes ni con los medios de prueba que estas aportan, reservando una eventual participación más activa solo hacia el final a propósito de las medidas para mejor resolver utilizadas en algunos casos para salvar los papeles de la Justicia a última hora.

Es cierto que no debe ponerse al mismo nivel la importancia de uno y otro problema. En efecto, cuando se defiende que el procedimiento debe estar guiado por la oralidad, vale decir, cuando se postula la superación de un sistema tan escrito (como el que ha regido en Chile y en otros países de la región; también en España) se debiera priorizar el objetivo de lograr un proceso de una superior calidad al actual. Aunque, evidentemente, el ideal es que se logre el ideal de una Justicia más rápida y de más calidad ${ }^{10}$. Las dilaciones pueden producirse igual en un proceso oral que en uno escrito y hasta existen experiencias de consagración de procesos orales en donde los tiempos de la respuesta jurisdiccional no se han bajado, sino que se han incrementado. Con todo, para ser justos, hay que decir que las estadísticas de duración de los procesos orales en países de referencia para nosotros, como lo son Uruguay y España, no pueden calificarse precisamente de malas, todo lo contrario ${ }^{11}$.

Pues bien, en las líneas que siguen afrontamos el tema en dos etapas o momentos. En una primera etapa, que se recoge bajo el punto II de este trabajo, nos referimos críticamente al modelo que actualmente tenemos, poniendo nuestra atención en las grandes marcas que derivan del mismo a partir de una concepción desequilibrada a favor de la forma escrita. No se lea esta parte, lo advertimos de inmediato, como una demonización de la escritura ni una exclusión de responsabilidad de otras causas en los problemas de nuestra Justicia ${ }^{12}$. En una segunda etapa - punto III- concentramos la atención en el análisis y reflexión de las modificaciones que, según se lee del trabajo hasta ahora realizado, debiera experimentar el modelo (declarativo) y que ligan, como se explicará, con la introducción de mayores grados de oralidad ${ }^{13}$. Sin perjuicio de reconocer de

\footnotetext{
9 TARUFFO (2008).

10 VÁZQUEZ (2008).

11 Poco más de siete meses en promedio para la primera instancia, y cinco meses en promedio para la apelación. Con un señalamiento de datos estadísticos bastante reveladores, véase: BONET (2008) p. 171; GiMENO (2007) p. 31. Respecto a la aceleración de los procesos judiciales lograda en Uruguay véase: PEREIRA (2008) p. 134.

${ }^{12}$ No puede pensarse que los problemas tienen su causa única en defectos procesales. No puede omitirse la característica escasez de órganos jurisdiccionales, la escasez de medios tanto materiales como personales y, desde luego, el continuo y progresivo aumento de los litigios.

13 En el estudio que realizamos evitamos incidir demasiado en las relaciones que en abstracto la doctrina ha destacado que existen entre la oralidad, la inmediación, la concentración y la publicidad. Tampoco podemos realizar un recorrido histórico del tema de la oralidad y la escritura en la doctrina procesal. No lo hacemos por tres razones. Una, la principal, es que este trabajo lo destinamos a un análisis de la apuesta por la oralidad en el Anteproyecto de nuevo CPC, y volver sobre estas cuestiones de corte generalista no aportaría en el debate en su fase actual. Dos, a estas cuestiones nos hemos referido con anterioridad, y un
} 
inmediato que se requiere de una definición en el modelo recursivo, estas líneas dicen relación con el formato de la primera instancia ${ }^{14}$. En este sentido, compartimos plenamente la afirmación del profesor De la Oliva ${ }^{15}$ que señala que la efectividad de la Justicia se juega en las instancias $y$, singularmente, en la primera instancia. En el punto IV recogemos resumidamente nuestras conclusiones.

A partir de la existencia de un Proyecto de nuevo CPC (anunciado por la Presidenta de la República el 21 de mayo pasado) creemos que conviene contribuir más concretamente en su estudio, análisis y crítica, único modo de ir avanzando en la consecución de un mejor producto final.

Al Proyecto antecedió un Anteproyecto redactado por una comisión mandatada por el Foro. El documento prelegislativo se estudió y analizó en el seno del Foro procesal civil, y en el marco de los distintos seminarios organizados por varias universidades que sin invitación ${ }^{16}$ se han comprometido con el proceso de difusión y análisis de los desa-

lector interesado en ellas podrá ilustrarse fácilmente a través de la consulta de nuestras publicaciones. Tras las limitaciones de espacio que nos imponen las normas editoriales de esta Revista, nos exige un análisis mucho más acotado y directo a los propósitos de este estudio. Nuestras publicaciones en este tema: PAlomo, D. (2005): "La prueba en el proceso civil chileno: ¿Una actividad asumida con suficiente seriedad? Una respuesta lamentablemente negativa”. Revista Normas Legales (Lima): Análisis Jurídico, Ed. Normas Legales, Tomo 352: pp. 253-261; (2004): "Modelo procesal civil chileno: Conveniencia de articular una nueva regulación sostenida en la oralidad como eje formal facilitador", Revista Gaceta Jurídica $\mathrm{N}^{\circ}$ 291: pp. 7-21; (2005): "Proceso civil oral: ¿Qué modelo de juez requiere?”. Revista de Derecho Universidad Austral, vol. XVIII, No 1: pp. 171-197; (2006): "Il processo civile cileno e la sua necessaria reforma", Rivista di Diritto Processuale (Milán), Cedam, N 3: pp. 1025-1040; (2007): "La necesaria reforma del proceso civil chileno: algunos apuntes", Revista Iberoamericana de Derecho Procesal (Buenos Aires) N¹0: pp. 217-245; (2004): "Y ahora, tras la experiencia procesal penal ¿La oralidad al proceso civil? Algunas claves y criterios", Revista Ius et Praxis, U. de Talca, N²: pp. 225-265; (2005): "La audiencia previa y el modelo procesal civil oral: Consideraciones en torno a una pieza procesal clave". Revista Chilena de Derecho, vol. 32, N 2: pp. 277-297; (2005): "Sobre el papel del juez civil en materia de prueba, especialmente de las medidas para mejor resolver. A propósito de la paradoja que evidencia nuestro sistema procesal tras la Reforma procesal penal”, Revista Gaceta Jurídica, N 300: pp. 7-18; (2006): “La apuesta de la nueva LEC española por la revalorización de la importancia del enjuiciamiento de primer grado: La nueva regulación de la ejecución provisional de las sentencias”. En coautoría con Rafael Hinojosa. Revista Ius et Praxis, U. de Talca, Año 12, N²: pp. 123-162; (2007): "Nuevo proceso civil español: Sobre algunas de las más positivas consecuencias de la apuesta por un modelo procesal oral, concentrado y sin intermediarios”. Revista de Derecho Universidad Católica del Norte, vol. 1: pp. 131-210. Además, pueden revisarse nuestros libros: PALOMO (2008): Oralidad en el proceso civil. El nuevo modelo procesal civil español (Santiago, Ed. Librotecnia) 700 pp.; De la Oliva y Palomo (2007).

14 El tema del modelo recursivo y su compatibilidad con la apuesta por la oralidad será objeto de un trabajo distinto. Con todo, la solución recogida en el Proyecto ya ha sido objeto de varias críticas que nos permiten adelantar que será objeto de una revisión profunda en sede legislativa.

15 DE LA Oliva. Esta afirmación la realizó en el marco de su conferencia "Algunas ideas para la formulación de un modelo de casación civil".

16 Distinto ha sido lo acontecido en otros países. Recordó el profesor De la Oliva en su reciente visita a Chile que en el caso de los primeros pasos de la reforma procesal civil española, tras elaborarse el denominado Borrador de nueva LEC por un grupo muy reducido de profesores, se procedió a remitir un ejemplar de este (en papel) a todos los profesores de la disciplina a objeto de nutrirse en verdad de observaciones y críticas. En otras palabras, se aseguraron de que todos pudieran dar su opinión respecto al producto que se había elaborado $y$ de que esa opinión fuese tenida efectivamente en cuenta. 
fíos de la reforma procesal civil. Tanto el Anteproyecto antes, como el Proyecto hoy, huelga decirlo, son demostrativos de que a estas alturas se impone la necesidad de materializar un nuevo sistema de enjuiciamiento civil, lo que a su turno implica asumir que no alcanza con la reforma parcial del actual centenario Código.

Aunque es evidente, y se desprende de lo recién dicho, este texto no puede entenderse como el producto final. Sostener esto sería alterar su propia naturaleza y, además, denotaría una falta de estudio del mismo, ya que a poco avanzar en su lectura evidencia omisiones, problemas y contradicciones que reflejan que aún existe importante tarea por realizar (importantes definiciones que tomar), en donde este texto solo constituye un importante punto de partida, la primera piedra (ni la última ni la única) de la cual debiera surgir la mejor articulación de una reforma procesal civil sostenida en forma predominante en la oralidad.

El desafío que nos mueve a escribir estas líneas se contextualiza en el proceso de reforma y apunta a situar el tema de la opción a favor de la oralidad y la escritura en una dirección razonable y practicable. En esta línea debemos adelantar algo de nuestra posición. Para quien escribe, el tema de la oralidad y la escritura no se agota en la decisión de la forma en que los distintos intervinientes se van a comunicar en el marco de un proceso. Dicho en otras palabras, y utilizando como ejemplo el mismo Anteproyecto, buena parte de la regulación que se propone viene determinada por una opción que se toma hacia la introducción de mayores grados de oralidad. A contrario sensu, varias (sino todas) las características (marcas) del actual modelo vienen determinadas por la opción exagerada que se tomó hacia la escrituración. Dicho esto, de lo que se trata es de evidenciar los roles de la oralidad y de la escritura en un proceso, sistematizando las marcas (de una y otra), para terminar contribuyendo con un estudio y análisis del concreto modelo que se propone en el Proyecto.

\section{MARCAS DEL CARÁCTER EXAGERADAMENTE ESCRITO DE LA ESTRUCTURA PROCESAL VIGENTE}

\section{A) Traspaso del modelo español}

De entrada se debe aludir a las Leyes de Enjuiciamiento Civil españolas de 1855 y 1881, ya que nuestro CPC es, en importante medida, heredero del modelo consolidado en aquellos textos legales y, con ello, del sistema del proceso ordinario que ya arrancaba de las Siete Partidas, produciéndose la consolidación de los principios y reglas propios del viejo proceso ordinario ${ }^{17}$.

Varias son las marcas que se podrían señalar como identificadoras de este modelo, pero lo más característico fue la condición rigurosamente escrita que tuvo el procedimiento. El solemnis ordo iudiciarius en gloria y majestad: complicación procesal, formalismo, lentitud y muy alto costo. Desde el punto de vista estrictamente procedimental: delegación, dispersión procesal, proliferación de incidentes, exclusivo impulso procesal 
de las partes, publicidad muy poco efectiva y un claro protagonismo del expediente. El brocardo jurídico quod non est in actis est in mundo no contó con contrapesos, especialmente tratándose del proceso civil prototípico, el juicio de mayor cuantía.

El modelo asumido y consolidado por las leyes españolas del siglo XIX fue recepcionado por la mayoría de los países latinoamericanos. Chile lo recoge en el Código de Procedimiento Civil de 1902 y lo mantiene, sin modificaciones importantes, hasta nuestros días. En efecto, si bien el CPC ha experimentado reformas parciales materializadas en distintas leyes, estas no consiguieron superar de verdad los problemas que aquejan a nuestra Justicia civil y que derivan de la lamentable mezcla entre una infraestructura y recursos humanos insuficientes y un modelo procesal -heredado de España como recién se apuntó- que ha reproducido en Chile y otros países latinoamericanos los problemas evidenciados durante todo el siglo XX en la Península ${ }^{18}$. La tradición y males del modelo procesal civil hispano -paradójicamente- perviven en nuestro país y en varios de nuestros vecinos, mientras que los propios españoles cuentan ya desde el año 2001 (LEC $1 / 2000$ entra en vigor un año después de su aprobación) con un nuevo y reconocidamente mejor modelo.

\section{B) MARCAS Y CONSECUENCIAS DE LA ADOPCIÓN DE UN MODELO TAN} ESCRITO

Cómo lo advirtiéramos, concentramos nuestro análisis solo en determinados elementos que nos servirán a la hora de analizar la reforma que se propone ${ }^{19}$. En este sentido lo primero es reconocer en el vigente modelo un diseño formal fundamentalmente basado en la escritura (y en el expediente), por tanto, un diseño procesal que contempla características muy similares a las existentes en el modelo español ahora derogado y superado. La escritura, regla que domina (casi) sin contrapesos, se muestra acompañada de elementos que han evidenciado una escasa conveniencia respecto a determinadas fases del proceso.

Cada una de las actuaciones del proceso civil se encuentra concebida desde y para la forma escrita ${ }^{20}$. Las escasas actuaciones orales que se contemplan están desvirtuadas por una práctica plagada de delegación. El juez debe pronunciar sentencia basándose exclusivamente en los actos realizados por escrito o en la documentación de los actos

\footnotetext{
18 Por ejemplo, la descripción que el profesor Pereira hace de los problemas del antiguo sistema uruguayo (anterior a la entrada en vigor del CGP en el año 1989) son coincidentes con la situación actual chilena: proceso lento, escrito, formal y burocrático, por un lado (las formas transformadas en un fin en sí mismas y no en un instrumento al servicio de los derechos sustanciales); juez mero espectador (ausencia de inmediación); un proceso de hecho transformado en reservado (falta de publicidad); delegación de funciones jurisdiccionales (por ejemplo, en la recepción de declaraciones de testigos, el interrogatorio de las partes). Véase: PEREIRA (2008) en: CABEZÓN (2008) pp. 188-190.

19 Los análisis podrían abarcar varias otras relaciones y efectos. A juicio de Damaska, las marcas dicen relación con la estructura general del sistema. La organización de una Justicia jerárquica influenciaría el diseño de los procedimientos. De hecho, la escrituración de un sistema presentaría indudables ventajas para la revisión de las resoluciones judiciales por los tribunales superiores. Véase: DAMASKA (2000).

${ }^{20}$ En este mismo sentido véase: CAROCCA PÉREZ (2003) pp. 56-57.
} 
que se hayan llevado a efecto oralmente. El sistema opera bajo la creencia de la superioridad absoluta de la escritura... verba volant y scripta manet.

El desmesurado arraigo de esta regla de la escritura en nuestro modelo procesal civil ha afectado también, como ha ocurrido en otros sistemas escriturados, a aquellos procedimientos en que el legislador, atendida la naturaleza de la acción deducida que requiere rapidez en su tramitación para ser eficaz, apostó por introducir mayores grados de oralidad. En efecto, las marcas de la escrituración se han expandido incluso a aquellos procedimientos en donde la ley contempló expresamente la oralidad, por ejemplo, en el procedimiento sumario que, no obstante las intenciones, resultó ser igualmente escrito en la práctica, muy fundamentalmente por la actitud de la judicatura y de los mismos abogados sumidos en una verdadera "cultura de la escritura".

Aparece claro que el diálogo forense se realiza en nuestro proceso civil con una clara característica, particularmente inadecuada y dañina (en su exceso) para determinadas actuaciones del proceso, especialmente en lo referido a la práctica de las pruebas. El diseño formal del proceso civil discurre y se desarrolla a través de escritos recogidos en soporte papel, material que se acumula en los tribunales chilenos. A su turno, cabe tener a la vista que cada papel que se presenta al tribunal genera nuevos papeles y nuevos actos, contribuyendo de este modo a que la respuesta jurisdiccional se dilate más.

Como consecuencia, es un modelo donde se echa en falta la inmediación y el contacto directo entre el juez con las partes, los testigos, los peritos y las demás fuentes de prueba. Se extiende la delegación, reservándose el juez prácticamente solo para la dictación de la sentencia ${ }^{21}$, pues el modelo escrito (disgregado) no aporta al juez estímulos para estar efectivamente presente. Tenemos un juez que por las consecuencias de la excesiva escrituración del modelo se ha convertido, como dijéramos, en un juez invisible, ausente, mero lector de los expedientes que se acumulan en su despacho. El proceso civil actual (como todo proceso civil tan marcadamente escriturado) es uno en el cual el justiciable (demandante o demandado) asiste a los actos judiciales de prueba o a otros trámites sin ver el rostro del juez que va a dirimir el conflicto ${ }^{22}$.

El proceso carece también de concentración y favorece la dispersión procesal retardando la decisión definitiva. Al contrario, el proceso se desenvuelve en base a una sucesión de plazos y se divide, preclusivamente, en distintas etapas; en este modelo

\footnotetext{
${ }^{21}$ La relación entre el juez y las demás personas que intervienen en un proceso está intermediada por otras personas, generalmente empleados del mismo tribunal, que han recibido la información, y la han transmitido en actas, que son las que leerá el juez que deberá dictar la sentencia definitiva. El modelo no incentiva la efectiva presencia del juez en la práctica probatoria. Lo contrario, en realidad. Por el diseño que impone la estructura escrita y desconcentrada de nuestro proceso, resulta prácticamente imposible que los jueces puedan dictar la sentencia con el recuerdo cercano de la prueba rendida (suponiendo que haya efectivamente asistido a dicha práctica probatoria). A lo anterior debe sumarse otra cortapisa contra la inmediación judicial, cual es que el sistema existente no impide la sustitución del juez durante la substanciación del juicio. En tal eventualidad, es uno el juez ante el cual se rinden las pruebas y otro aquel que finalmente debe resolver el asunto. Esta posibilidad atenta contra la inmediación en su sentido estricto que, como se sabe, bien exige que el juez que resuelva al asunto sea el mismo que haya presenciado la práctica de las pruebas, única manera, por lo demás, que la regla procesal no sea vaciada de contenido.

22 VÁZQUEZ (2008).
} 
formal ni siquiera las pruebas son practicadas concentradamente. Igualmente, el modelo permite la promoción de incidentes a lo largo de todo el proceso, prácticamente desde antes que este se inicia hasta que termina ${ }^{23}$. En otras palabras, la forma escrita y desconcentrada de nuestro modelo trabaja en unos tiempos que son necesariamente mayores, nada compatibles con una realidad económica y social muy diferente a la que existía al momento de entrar en vigente el actual CPC.

Pero la falta de inmediación y concentración no solo afecta los tiempos de la respuesta jurisdiccional, sino que también contribuye decisivamente en lo que dice relación con la ausencia de calidad del modelo en punto a que, como bien se ha destacado, cuando la prueba no se concentra, el expediente escrito pasa a ser la única fuente disponible para quien debe juzgar los hechos ${ }^{24}$, con lo cual se consolida una separación entre el juez y estos, postergándose de este modo el juicio de hecho y con ello el fondo y la calidad de la decisión (en definitiva, un factor que termina atentando contra la calidad de la Justicia).

Se posterga así la actividad más trascendente del proceso, el alma del proceso se le ha denominado, entregándola a sujetos intermediarios. Los evidentes límites de la transcripción escrita contenida en las actas levantadas por estos intermediarios termina afectando la calidad de la decisión. Por ejemplo, el sistema formal escrito actual no brinda entrada a las posibilidades del denominado lenguaje no verbal, que queda fuera de la transcripción escrita. Los silencios, el grado de firmeza en las respuestas, el grado de convicción demostrado por el tono de la voz o por la actitud de quien contesta, no pueden tener prácticamente ninguna cabida. En este esquema de trabajo, el juez chileno acostumbra fallar solo leyendo el expediente que se pone a su disposición, de allí que hablemos del paradigma o modelo de juez lector ${ }^{25}$.

Por eso es que una reforma que por estar bien diseñada e implementada permita dejar atrás este esquema de trabajo debe considerarse -indudablemente- un salto cualitativo en la Justicia y es justamente a esta mejora en la calidad a la cual deben dirigirse los mayores esfuerzos.

Podemos decir entonces que tenemos un modelo que posee una estructura formal que, junto con constituirse en un factor importante en los retrasos, tampoco cautela la

\footnotetext{
${ }^{23} \mathrm{La}$ existencia de tales incidentes, en ocasiones llega a consumir gran parte del tiempo y de las energías de las partes y de los jueces, retardando por largísimo tiempo los procesos. CAROCCA Pérez (2008) p. 58.

24 TARUfFo (2008).

25 Cappelletti se refirió a las marcas de la excesiva escrituración de un modelo procesal. Según él este tipo de procesos (escritos) tiene varias características, las cuales, generalmente, aparecen relacionadas íntimamente y que son las que distinguieron al proceso común (romano-canónico). En primer lugar es el de la escritura presidido por el principio de que quod non in actis non est in mundo; en segundo lugar la ausencia de todo contacto directo entre el juez y las partes y también los peritos y testigos o toda otra fuente de información como lugares y cosas. El tercer carácter es el criterio de apreciación legal de la prueba (o prueba tasada), quitándole al juzgador toda posibilidad de buscar por sí la verdad. El cuarto carácter es el de la realización del procedimiento en etapas separadas y clausuradas en términos preclusivos en las cuales se va desarrollando el trámite. Las escrituras provocan contraescrituras, decía Cappelletti, que se van escalonando en un interminable lapso provocando la excesiva duración del trámite. Quien desee profundizar en el pensamiento del maestro florentino, véase: CAPPELLETTI (1971).
} 
calidad de la decisión. Existe una evidente insatisfacción por los tiempos y por la calidad de la prestación jurisdiccional prestada por los tribunales civiles ${ }^{26}$.

Todos estos antecedentes hacen no dudar de la necesidad de un cambio mayor, un cambio en el modelo formal imperante que vaya más allá de un mero maquillaje o parcheo pretendidamente reparador. Se requiere de cambios en la actual estructura formal, apostando por una que, permitiendo una distribución más razonable del trabajo judicial, permita superar los problemas actuales.

\section{LA ORALIDAD EN LA JUSTICIA CIVIL Y LAS MARCAS QUE SE EXPRESAN EN EL MODELO QUE RECOGE EL PROYECTO27}

\section{A) EN LA BÚSQUEDA DEL EQUILIBRIO}

\section{La oralidad a la Justicia civil: necesidad de evitar modas y mitos}

Hemos aludido a la estructura (exageradamente) escrita del modelo procesal civil chileno como factor relevante en dos importantes problemas de eficiencia: el excesivo tiempo de la respuesta jurisdiccional y su deficiente calidad. Pues bien, en esta parte comenzamos a revisar la propuesta de reforma que se contiene en el Proyecto, y lo hacemos desde la perspectiva anunciada, esto es, analizando las principales marcas de la apuesta hacia la oralidad que se propone en pos de superar los problemas asociados al actual modelo escrito. Para ello es conveniente comenzar por poner en contexto la situación de nuestra particular reforma procesal civil dentro del gran tema de la introducción de la oralidad en la Justicia civil.

Este tema es ya un clásico en el Derecho procesal, lo que no implica que haya perdido interés en la actualidad. Una calificada muestra de esta actualidad fue el Coloquio Internacional Oralidad y Escritura en un proceso civil eficiente realizado a fines del año pasado por la Asociación Internacional de Derecho Procesal en Gandía (España). Bajo la coordinación del profesor Ortells, permitió reunir una gran cantidad de participantes de las más variadas procedencias para hablar justamente de la oralidad (y la

\footnotetext{
26 Los resultados de un estudio reciente muestra que un mayor uso de la escritura va asociado a una Justicia de peor calidad. "Cuando aumenta el uso de la escritura los ciudadanos, según los resultados de la encuesta, manifiestan que los tribunales son menos justos, más corruptos, menos coherentes, las resoluciones de menor calidad, la gente piensa que se puede confiar menos en ellos y el predominio del Estado de Derecho es menor". RAMOS (2008).

27 Hay que insistir en que las principales acciones que deben adoptarse para hacer frente a los problemas de la Justicia civil chilena pueden manifestarse a través de dos tipos de reformas: las denominadas reformas orgánicas, que persiguen fundamentalmente a aumentar el número de jueces y funcionarios; y las reformas de corte procedimental, que apuntan al mejor y más razonable diseño formal, a la mayor simplificación, a la facilitación de los trámites, a la supresión de formalismos procesales que se muestran innecesarios y a la incorporación de institutos hasta ahora inutilizados. A estas últimas nos referirnos ahora, sin perjuicio de reconocer que la solución integral siempre pasa por la comunión de las reformas señaladas. Así se ha reconocido también en informe antes citado, en donde el listado de propuestas de cambios en el sistema de Justicia civil es encabezado por la necesidad de aumentar los recursos humanos de los tribunales seguidos de la reforma y simplificación de los procedimientos, véase: GUTIÉRREZ y MALDONADO (2006) p. 44.
} 
escritura) en el proceso civil con la mirada puesta en la búsqueda de las fórmulas más provechosas de cara a la eficiencia del proceso $^{28}$.

Fundamentalmente a partir de la Ordenanza Procesal civil alemana de 1877 (hito muy importante por su repercusión al convertirse en la base de todas los ordenamientos europeos posteriores) y por la obra de Klein en la Ordenanza Procesal Civil austríaca de 1895 , es que algunos autores comienzan a abogar decididamente en favor de la introducción de la oralidad en la Justicia civil ${ }^{29}$. Destaca en esta labor la actividad de insignes procesalistas tales como Chiovenda y Cappelletti ${ }^{30}$. También se deben tener en cuenta las aportaciones en el tema de Rosemberg, Devis, Prieto y Fairén ${ }^{31}$.

La oralidad en la Justicia civil, como bien se ha recordado en el citado Coloquio, ha dado lugar a encendidas discusiones y a reformas de diferente signo (y éxito) ${ }^{32}$. Lo que ocurre es que nuestro país se está recién incorporando a este debate con más un siglo de desfase, al igual que lo acontecido en España, país que solo reformó (sustancialmente) su modelo procesal civil con la Ley 1/2000, de Enjuiciamiento Civil ${ }^{33}$.

28 Destacando la plena vigencia del tema de la oralidad en el proceso, véase especialmente: STORME (2008).

29 Con fuente germánica y austríaca los principios que se asociaron a la oralidad se propagarían a otros países, expandiendo su influencia en todos los continentes y sistemas procesales contemporáneos. Véase: CARÚs (2003) p. 31.

${ }^{30}$ En lo que dice relación con Chiovenda, por su actividad realizada desde principios del siglo pasado hasta los años 20, es identificado como un apóstol de la oralidad asignándosele responsabilidad en la propagación de un verdadero mito en torno a ella. En él la forma oral alcanza niveles cercanos a la de un verdadero dogma formal, respecto del cual asume una declarada defensa. En efecto, comprometido por la adecuación del Código Procesal Civil italiano de 1865 a las condiciones de la sociedad y cultura de su época, protagonizó una campaña reformadora centrada en destacar al proceso oral como el mejor de todos los posibles, y el más conforme con la naturaleza y exigencias de la vida moderna que, sin comprometer las bondades intrínsecas de la justicia, la proporciona y asegura más económicamente, más simplemente y más prontamente. Chiovenda -en su entusiasmo- sitúa a la oralidad al nivel de verdadera panacea para los principales males que arrastra el proceso civil.

En Cappelletti la defensa de la oralidad estuvo centrada en su identificación como forma de facilitación del acceso a la justicia. Sostuvo (destacando la fuerza y utilidad de la oralidad) que el sentido del proceso oral es un proceso más rápido, concentrado, eficiente y un proceso más fiel a una metodología concreta y empírico-inductiva dentro de la investigación de los hechos y la apreciación de las pruebas. Con todo, aquí la diferencia, evitó plegarse al discurso chiovendano que planteaba a la oralidad como una panacea a los males del proceso civil, sino que concentró sus esfuerzos en destacar el valor instrumental de la oralidad conveniente para lograr procedimientos accesibles, simples y económicos. El proceso oral no ya como el "mejor de todos los posibles", y como "el más conforme con la naturaleza y exigencias de la vida moderna" como postuló Chiovenda, sino que el proceso oral como el único que permite el efectivo acceso a la Justicia, que se considera factor fundamental para el cumplimiento del fin social del proceso. En especial el acceso de aquellos que por su condición económica y cultural no están en condiciones de afrontar los costos, los formalismos y la duración excesiva de un proceso "escrito".

Véase al respecto: PAlOmo (2008) pp. 50 y ss.; CARús (2003) p. 31.

31 Por los límites de espacio no podemos detenernos en el pensamiento de cada uno de estos autores. Un resumen de estas aportaciones puede verse en MARTín (2008), donde se expone un recorrido histórico y actual del "principio" de la oralidad y su contraposición con la escritura.

32 Carpi, F. "Presentación”, en Coloquio de Gandía (fecha de consulta: 13 de noviembre).

${ }^{33} \mathrm{Al}$ respecto véase: PALOMO (2008) 689 pp. 
Paradójicamente, este retraso del modelo nacional puede resultar útil a la hora de reformarlo. En efecto, el desfase puede (debe) aprovecharse para evitar cometer los errores a los que muchos se empeñan en llevarnos. Es que -como ha dicho De la Olivasi bien sobre la oralidad en el proceso civil han corrido caudalosos ríos de tinta, "estos cursos fluviales poco o nada han fecundado ni la teoría ni la realidad procesales"34. Así ha señalado categóricamente: "Especialmente inútiles y tediosas consideraba y sigo considerando las apologías genéricas de la oralidad frente a la escritura, con tintes maniqueos y con presupuestos axiomáticos absolutos. Según ese maniqueísmo, la oralidad es el bien y la escritura, el mal. Y, bien mirados, los presupuestos aludidos han sido y son en muchos lugares la moda y la ideología, ambas desnudas de justificación, ambas presentes como quien, muy pagado de si mismo, piensa que ha de ser protagonista exclusivo por méritos que considera notorios e indiscutibles... aunque, en el fondo, nadie conozca esos méritos ni haya tenido la oportunidad de discutirlos".

La asociación de la oralidad con el progresismo y la modernidad está bien instalada entre nosotros, pero no por ello se puede compartir en el único sentido que algunos postulan ni se pueden ignorar los riesgos de algunos planteamientos tan alejados de la realidad que pretenden regular. En efecto, no se puede compartir que con una visión tan reduccionista como irreal se califique o entienda a la escritura como conservadora y la oralidad como progresista. Acaso, expresivamente se ha apuntado: " $E$ Es la escritura cavernicola y la oralidad moderna?"35. No son pocos los que han sostenido -especialmente en Latinoamérica- que la apuesta por la oralidad en la Justicia civil debe significar necesariamente asumir un "bloque" que se asocia indefectiblemente a la modernidad procesal ${ }^{36}$. Cualquier variación en el contenido que algunos asignan a este "bloque" es apuntado y denunciado como una renuncia al progresismo y, por ende, una verdadera concesión al que denominan conservadurismo procesal.

Por fortuna, pareciera que este discurso irreflexivo a favor de una oralidad desbordada que menosprecia la utilidad y conveniencia de la escritura en su justa medida va encontrando fin. Van ganando terreno aquellos planteamientos que, con más realismo y menos doctrinarismo de posibilidades meramente teóricas, no descartan la utilidad de la escritura para algunas fases y actos del proceso civil, e instan por la oralidad en otros ${ }^{37}$. Un ejemplo del desmarque de la versión mitológica que ha caracterizado a los análisis sobre la oralidad es el trabajo de Nieva Fenoll, profesor titular de Derecho procesal de la Universidad de Barcelona, que da cuenta de los inconvenientes y deficiencias que puede

\footnotetext{
${ }^{34}$ DE LA Oliva (2008).

35 DE la Oliva (2008).

36 Entre las consecuencias del uso de la oralidad, identificadas con el movimiento de publicización del proceso, estarían las siguientes: la concentración de las actuaciones procesales, la inmediación judicial, la publicidad del proceso, la atribución de poderes al juez en materia probatoria, la utilización de la sana crítica para la valoración de la prueba, la atribución al juez de poderes disciplinarios, y la inexistencia de recursos devolutivos contra las decisiones interlocutorias que se dictan en el proceso. RAMOS (2008).

37 Algunos ya postulaban estas ideas años atrás, cuando la generalidad de la doctrina transitaba en otra dirección: De la Oliva (1999); PALOMO (2004) pp. 225-265. En un texto de reciente publicación afrontamos el tema de la oralidad y la escritura desde esta perspectiva: PALOMO (2008).
} 
presentar la oralidad, a la vez de destacar las ventajas de la escritura para determinadas fases del proceso ${ }^{38}$.

Las señales recibidas en el último tiempo son en importante medida satisfactorias puesto que se asume que la cuestión de la oralidad en el proceso civil es una cuestión de grados y que ya es hora de ir dejando atrás los mitos a ella asociados ${ }^{39}$. Se comienza a asumir la necesaria coexistencia de elementos escritos y de elementos orales, por lo que el problema de la oralidad y de la escritura se empieza a abordar -de verdad-como un problema de predominio o de coordinación, y no como un asunto de exclusión. A pesar de que razonablemente no podía ser de otro modo (y que la misma realidad muestra que no existe un proceso que sea puramente oral), ciertos autores se han prodigado, especialmente durante el siglo XX, en intentar planteamientos cercanos a un doctrinarismo sin sentido.

Ortells apunta con claridad que lo que debe buscarse en punto a esta cuestión de la oralidad y la escritura en el proceso civil es la ecuación precisa que permita contribuir de verdad a la obtención de un proceso civil eficiente ${ }^{40}$. Se trata, en otras palabras, de buscar la adecuación entre las formas del procedimiento y el logro de los fines del proceso civil, dando paso a la introducción de mayores grados de oralidad allí donde se le requiere y manteniendo la regla escrita allí donde resulta conveniente conservarla.

De hecho, cuando el adecuado término medio entre la oralidad y la escritura se ha encontrado los resultados han sido muy buenos ${ }^{41}$.

\footnotetext{
38 Señala: “... creo que ha llegado el momento de que se descubran algunos de los inconvenientes de este principio del procedimiento, no desde la pura teoría, sino desde la experiencia de lo que está siendo la oralidad en la práctica. El recuento de desventajas ha sido casi siempre realizado con respecto al procedimiento escrito, porque es él el que se había venido padeciendo desde hacía muchos siglos tanto en lo civil como en lo penal, e interesaba luchar contra algo que había provocado tantísimos retrasos -puramente burocráticos muchas veces- en el proceso. Pero la oralidad no está exenta en absoluto de problemas". NieVA (2007).

39 Para Taruffo existen dos mitos asociados a la idea de la oralidad. El mito positivo: la oralidad como valor óptimo básico, una especie de panacea que debiera resolver todas las dificultades del funcionamiento del proceso civil. Y el mito negativo: la escritura es esencialmente perversa y responsable de la mayoría de los problemas que surgen en un litigio civil, por lo que debiera reducirse al mínimo, o bien anularse. TARUFFO (2008).

40 ORTELLS, "Necesidad del encuentro", en Coloquio antes citado (fecha de consulta: 13 de noviembre).

${ }^{41}$ En efecto, en aquéllos países con sistemas basados en procesos predominantemente orales (como Alemania y España), pero que no descartan la oralidad (ni la demonizan) tienen un mejor historial en lo que a procesos acelerados se refiere y, en general, sus usuarios muestran mayores grados de satisfacción. España, ya lo dijimos antes, brinda un buen ejemplo en punto al mejoramiento de los índices de satisfacción de los usuarios del modelo procesal civil. Los abogados españoles, que en un principio se opusieron fuertemente a la LEC 1/2000 hoy se muestran claramente conformes. El diseño del procedimiento y de sus audiencias (y la implantación efectiva de las modernas tecnologías de registro y reproducción de la imagen y el sonido) ha "forzado" el cumplimiento de la inmediación judicial, fortaleciéndose de este modo el juicio de hecho, el fondo y la calidad de la decisión. Respecto al proceso civil alemán, véase: PÉrEZ y OrTIZ (2006). Respecto del nuevo modelo español, véase: PALOMo (2008); De la Oliva y Dí́zZ-PiCazo (2003).
} 


\section{Referentes: el Código Modelo y la LEC española ${ }^{42}$}

\section{El Código Modelo}

Un antecedente relevante -por la influencia que ha tenido en la Región y desde luego en los que han elaborado el Anteproyecto y Proyecto de nuevo $\mathrm{CPC}^{43}$ - en cuanto a las directrices que en esta materia debiera tener a la vista nuestro modelo está dado por la existencia desde 1988 del Código Procesal Civil Modelo para Iberoamérica ${ }^{44} 45$.

En lo que a efectos de este trabajo nos interesa, el Código Modelo apuesta por la oralidad. Ya lo adelantaban las bases para la preparación del Código, cuando propugnaban que debía procurarse la implantación del proceso oral como la solución más eficaz contra la excesiva duración del proceso, y como elemento que permita la efectiva realización de los principios de publicidad, inmediación y concentración.

Buscando revertir el sistema actual de proceso escrito en Iberoamérica "desesperadamente escrito", como le llamara Couture, lento, pesado, burocrático y alejado de la realidad, se apuesta por la oralidad, postulando un modelo de proceso civil por audiencias. En todo caso, el predominio de la forma oral que se postula no alcanza a negar las virtudes y ventajas de la escritura. De hecho, en este modelo son escritas la etapa de proposición (por lo tanto, son escritas la demanda, la contestación y la eventual reconvención) y la de recursos. Pero dejando a un lado estas actuaciones, la idea de audiencia aparece como central ${ }^{46}$.

\footnotetext{
${ }^{42}$ Nos detenemos brevemente en este punto en la revisión de dos referentes externos: el Código Modelo y la nueva LEC española. Naturalmente, no ignoramos que dentro de nuestro sistema también contamos con modelos que recogen una oralidad predominante, como lo es el Código Procesal Penal, la Ley de Tribunales de Familia y el Código del Trabajo tras la última reforma. Este proceso de reforma de la Justicia civil debe sacar los aspectos positivos de estas reformas, desechando aquello que no ha mostrado buenos resultados. Un mero ejercicio de comparación de textos legislativos evidencian que tanto la reforma a la Justicia de Familia como a la Justicia Laboral tuvo como referencia el modelo español.

43 Se conoce que este Código ha sido el sustento en sus aspectos medulares para la reforma realizada en 1989 -con muy buenos resultados- en Uruguay. En efecto, tras casi veinte años de aplicación de la reforma en este país, ésta muestra un desempeño general positivo que convierte a la experiencia uruguaya en referencia obligada para otros países de la Región. Un ilustrativo estudio teórico y empírico en: PEREIRA (2008) 134 pp. Véase también: Pereira (2008); Pereira (2005). Se sabe también que la influencia del Código Procesal Civil Modelo ha alcanzado también a otros procesos de reforma actuales, entre ellos se cuentan los casos de Colombia, Guatemala y Nicaragua, entre otros países. Véase: Villadiego, C. "Avance en América Latina y el Caribe de la reforma a la Justicia civil”, en: CABEZÓn (2008).

44 Véase: Instituto Iberoamericano de Derecho Procesal (1994).

${ }^{45}$ Este Código representa un valioso trabajo que se puso a disposición de los legisladores locales a fin de proveerles de una base sobre la cual plantear sus respectivas reformas procesales. Pues bien, su influencia no se ha limitado a nuestra región. Ha despertado un interés que ha trascendido a ella. Prueba de este interés fue la celebración en septiembre de 1988 de un Congreso Internacional en Roma, patrocinado por la Universitá di Roma II (Centro Interdiciplinari di Studi Latino-Americani) y la Associazione di Studi Sociales Latino-Americani (ASSLA), evento que contó con la participación de especialistas italianos y de miembros del Instituto Iberoamericano de Derecho Procesal. Intervenciones de este importante Congreso véanse en: SCHIPIANI y VACCARELLA (1988).

46 Véase la Exposición de Motivos del Código Modelo en: Instituto Iberoamericano de Derecho Procesal (1994) p. 48.
} 
Entre las audiencias que se contemplan destaca la audiencia preliminar que tempranamente reúne al Tribunal y las partes. En el desarrollo del procedimiento, se explica en la Exposición de Motivos, adquiere una importancia fundamental, pues se le reconoce un complejo contenido en donde el fin primordial es evitar el litigio (función de exclusión del proceso que se concreta a través de la conciliación) o, si este objetivo no se logra, limitar su objeto, determinar la prueba y depurar (sanear) el procedimiento. A esta audiencia preliminar sigue una segunda (si el proceso no ha terminado por la conciliación) destinada a la práctica de las pruebas, breves alegaciones orales de las partes y la sentencia del tribunal. Se busca y procura que el juez adelante su fallo en ese acto, aunque luego se expidan los fundamentos en un plazo breve posterior.

En lo que aquí nos interesa, se postula en este Código Modelo (artículos 1-11, Título I del Libro I: principios generales) un modelo procesal predominantemente oral, en donde la dirección del proceso está confiada al Tribunal por lo que promovido el proceso el Tribunal tomará de oficio las medidas tendientes a evitar su paralización y adelantar su trámite con la mayor celeridad posible. La apuesta por un modelo oral implica aquí la publicidad del proceso, la inmediación procesal (por lo que todas las audiencias como las diligencias de prueba que así lo permitan se realizarán por el Tribunal no pudiendo este delegarlas so pena de nulidad absoluta) y la concentración.

En este lugar hablamos de las orientaciones atendibles del Código Modelo. Consideramos que el Código lo es (o puede ser) en varios aspectos, entre los que cuenta el modelo de procesos por audiencias que recoge. Sin embargo, en otros aspectos su propuesta resulta más que discutible, especialmente en aquéllas normas que son el reflejo de la consagración de la doctrina de la publicización del proceso civil. Algunas de ellas están recogidas en nuestro PCPC, razón por la cual la crítica nos la reservamos para el lugar en el cual realizamos el análisis de este Proyecto. Solo adelantamos, como ya es bien conocido por lo demás, que no compartimos aquellas posiciones doctrinales que asocian la introducción de la oralidad con un mayor protagonismo del juez en materias ya no solo procedimentales, pretendiendo - por ejemplo- conferirle amplios poderes en materia de iniciativa de las pruebas. Es en este punto donde creemos que resulta útil y necesario el ejercicio de no dejarse llevar por un exceso de doctrinarismo inútil que pueda afectar las bases sobre las cuales, a nuestro juicio, se debe construir razonablemente un proceso civil.

\section{La LEC española y la oralidad}

El otro referente que no se puede desatender para la reforma (a pesar de la oposición de algunos que prefieren atender a sistemas que resultan ajenos a nuestras tradiciones $)^{47}$ está dado por la LEC $1 / 2000$ española ${ }^{48}$. Sin duda que se trata de un

\footnotetext{
${ }^{47}$ Lo que naturalmente no obsta a valorar y estudiar la posibilidad de la incorporación de determinados institutos generados y desarrollados en un sistema procesal perteneciente a otra familia jurídica.

48 Como ya se apuntó antes, desde el comienzo de nuestra codificación procesal las leyes procesales españolas han sido referentes obligados, tanto por la comunidad cultural, como por la facilidades que otorga la misma lengua. De hecho, el modelo procesal nuestro actual, CPC, es heredero del modelo español consagrado a través de las LEC de 1855 y 1881.
} 
referente que se ha venido teniendo a la vista, más aún cuando la apuesta por introducir y reforzar la oralidad sea una de las novedades de esta Ley más reconocida y valorada por todos los sectores que se interesan por la Justicia civil española (ciudadanos, abogados, jueces y autores), lo que demuestra que su implementación práctica ha sido -contrariamente a lo que algunos vaticinaron- en general exitosa.

En efecto, sin entrar aquí en un análisis detallado de la nueva normativa, lo que se destaca es que, tras una preferencia absoluta (y excesiva) por la forma escrita, la LEC asume la conveniencia de introducir y reforzar la oralidad en el proceso civil. Lo hace también recogiendo un modelo de proceso civil por audiencias. El legislador español valora especialmente la concentración de las actuaciones e intenta rescatar la inmediación judicial, perdida en una práctica judicial gobernada por la delegación de funciones jurisdiccionales que atentaban contra la calidad de la Justicia ${ }^{49}$.

Sin asumir una oralidad extrema (por lo tanto, reconociendo la relevancia y trascendencia de la escritura para ciertos actos del proceso), la decisión de cambiar el predominio formal marca al nuevo modelo en diversos sentidos a los que es imposible referirse en tal limitado espacio. La revalorización de la actividad probatoria (en la prueba está radicado el epicentro del cambio y superación de la desmejorada situación que rigió bajo la LEC anterior), la reformulación de las antiguas diligencias para mejor proveer y la nueva configuración legal de la ejecución provisional de las sentencias (que está funcionando muy bien) se cuentan entre estas marcas.

Gascón lo resume bien: “... sobre todo, la oralidad, la concentración y la inmediación contribuyen a una respuesta judicial más correcta y más justa, en la medida que se ve muy reforzado el valor de lo actuado por las partes y sus abogados en el proceso; en especial, se ve muy reforzado el valor de las pruebas de todo tipo y, singularmente, de las pruebas personales, de las que se pueden extraer dosis mucho mayores de convicción en el marco de un debate oral en presencia judicial que de la simple lectura de un acta de comparecencia"s0 Allí, en gran medida, encuéntrese la explicación a la restricción en la regulación de las diligencias finales (se quiere ser consecuente con la centralidad del juicio)... allí también la explicación para la valiente asunción del "riesgo" que implicaba para algunos una ejecución provisional más sencilla, por lo tanto, más amplia ${ }^{51}$.

\section{B) EL PROYECTO, LA ORALIDAD Y SUS MARCAS 52}

\section{El terreno de las formas: opciones que tiene el legislador}

Entrando derechamente al análisis de la apuesta formal que recoge el Proyecto, para la cabal comprensión de este asunto creemos caben algunas puntualizaciones y

\footnotetext{
49 Véase, para mayor ilustración, la Exposición de Motivos de la LEC.

${ }^{50}$ GASCÓN (2008) p. 183

51 Sobre estos puntos en particular, en Chile, véase: PALOMO (2007).

52 El Proyecto (así como el Anteproyecto) busca responder a las llamadas "Bases". Véase estas últimas en la Revista de Derecho Procesal de la Universidad de Chile, No 20 (2005): pp. 437 y ss. Véase el Anteproyecto en la Revista de Derecho Procesal de la Universidad de Chile, No 21 (2008): pp. 25 y ss. También en la Revista Estudios de la Justicia, No 8 (2006): pp. 41 y ss.
} 
explicaciones previas. En efecto, lo primero que se debe señalar es que una vez asimilada la necesidad de la reforma procesal civil entre nosotros, fundamental resultaba que se entendiera una cosa bastante obvia a estas alturas, pero también bastante olvidada por algún sector que ha pretendido llevar la apuesta hacia la oralidad hacia extremos que la experiencia acumulada durante el siglo $\mathrm{XX}$ se ha encargado de demostrar su fracaso.

Esta cuestión -elemental- no es otra que entender que los procesos son realidades artificiales, que por lo tanto no preexisten a su regulación por el legislador, sino que nacen con ella ${ }^{53}$. De este modo, todo proceso es una creación del legislador, quien tiene a su cargo la misión de disponer de las piezas a su alcance de modo que el producto final de su trabajo sea un instrumento que se acerque lo máximo posible a la justicia y a la eficacia en la solución jurisdiccional de los conflictos jurídicos.

Pues bien, en esta labor de creación el legislador no es absolutamente libre, dado que se encuentra limitado por el deber de respeto de varios principios sin los cuales no puede siquiera hablarse verdaderamente de proceso. Nos referimos -huelga decirlo- a lo que entre nosotros se denominan los principios del debido proceso, o garantías procesales (que en otras latitudes conocen bajo el nombre de principios jurídico naturales): principio de audiencia (audiatur et altera pars), de igualdad y de contradicción. El proceso se deberá configurar por el legislador de modo que siempre sean efectivos y respetados determinados postulados elementales de justicia, de allí su carácter necesario ${ }^{54}$.

En segundo término, el legislador también está limitado por otra clase de principios, cuyo objetivo es ajustar el instrumento procesal a la finalidad de tutelar eficazmente. Velando por esta necesidad, bien se ha dicho que los procesos se deben construir según criterios diferentes, los que se consideran más adecuados a la realidad jurídica en función de la cual aquéllos tienen sentido; se trata, en definitiva, de principios procesales que no configuran siempre los procesos, sino que inspiran ciertos procesos unos y otros procesos, otros. Surgen en este plano los principios dispositivo y de aportación de parte, en oposición de los principios inquisitivo y de investigación de oficio. Se les denomina principios jurídico técnicos ${ }^{5}$.

En el caso de los procesos para la tutela de bienes jurídicos que tengan una fisonomía netamente individual (previstos para la tutela de derechos privados; vale decir, los procesos de dinero a los que aludiéramos citando a Montero al inicio de este trabajo), parece lógico que se haga depender en gran medida de la voluntad y actuación de los interesados. Así, de los sujetos dependerá el inicio del proceso (nemo iudex sine actore), su configuración y delimitación (incluso su término), además de la carga de aportar al proceso las pruebas que comprueben la veracidad de las afirmaciones introducidas (iudex iudicet secundum allegata et probata partium).

53 Carreras (1962) pp. 51-62; De la Oliva y Díez-PiCazo (2004) pp. 44-45.

54 DE LA Oliva et al. (2003) p. 56.

55 DE LA Oliva et al. (2003) p. 56. 
En cambio, en el terreno de las formas (no hablamos de principios) ${ }^{56}$, esto es, en la configuración externa del proceso y del procedimiento no existen imperativos, sino que existen opciones. Pues bien, la opción principal está dada por la dupla oralidad-escritura, y constituye función del legislador apostar por el predominio de una u otra.

Las reglas procesales, entre ellas destacadamente la oralidad y la escritura, poseen un predominante carácter técnico; de allí que estén disponibles para el legislador que debe saber darles la mejor utilización posible de acuerdo a criterios de conveniencia y oportunidad $^{57}$. Claro está que la elección no será gratuita, pues de ella derivarán consecuencias (marcas), empero asignarles una jerarquía que no tienen significaría caer con facilidad en soluciones que no contribuyan al mejor desenvolvimiento del proceso civil.

Pues bien, frente a la identificación del carácter excesivamente escriturado del modelo vigente como la causa de los principales problemas del mismo, una tentación en la que se podía caer en el PCPC estaba dada por el asumir - a ultranza y con un maniqueísmo poco inteligente- la idea de la oralidad, desechando las ventajas que puede y debe aportar la escritura ${ }^{58}$.

Correctamente a nuestro juicio el texto que se propone no desecha las ventajas de la forma escrita para ciertos actos del proceso. No se cae en el maniqueísmo de ensalzar la oralidad como el Bien y demonizar la escritura como el Mal, de modo tal que se logra un diseño en el cual la forma escrita se reserva para aquéllas actuaciones donde es necesaria y razonable.

\footnotetext{
56 Seguimos lo que señala Andrés De la Oliva: "No es acertado ni conveniente, desde ningún punto de vista, denominar principios a todos los criterios generales en virtud de los cuales se opta por regular de un modo o de otro el proceso o ciertos aspectos o actuaciones de este. Para esos criterios resulta preferible utilizar los conceptos y términos de reglas o máximas. Como he dicho en otros lugares y ocasiones, cuando todo son principios, nada es principio. Y lo mismo sucede cuando a cualquier posibilidad de actuación humana se le denomina derecho: cuando todo son derechos, nada es derecho. Semejante amplitud conceptual no conduce a nada positivo”. DE LA Oliva et al. (2003) p. 56.

57 Con ello estamos destacando el carácter contingente de las formas procesales, que se opone a la jerarquía de verdaderos principios procesales con que parte de la doctrina pretende arropar a la oralidad y sus reglas conexas.

58 Bien se ha expuesto que resulta difícil de entender como se puede explicar seriamente una contemplación y un tratamiento de la oralidad y la escritura en el proceso "como formas en régimen de alternativa excluyente: ¿Cómo negar las ventajas de la escritura para ciertos actos? ¿Cómo no reconocer, para otros actos, no ya las ventajas, sino la necesidad de la oralidad?" (...) “Es lo mismo acaso escuchar que leer un texto que explica una realidad compleja? Lo escrito permite un estudio (relectura, anotación, detenimiento personalizado en ciertos pasajes) imposible cuando se trata de escuchar, incluso si cabe escuchar algo registrado y avanzar y retroceder para volver a escuchar. ¿Por ventura preferimos leer el texto de una obra teatral a presenciar su escenificación? ¿Acaso no escogemos escribir cuando hemos de transmitir datos numerosos y precisos y consideraciones complejas, que exigen distinguir, matizar, separar y relacionar?". Concluye en forma lógica: "Los procesos han de acoger actos escritos y actuaciones o actos orales, los procesos han de ser escritos y orales. No orales o escritos". Hay que mirar con recelo lemas como aquéllos que se titulan "de la escritura a la oralidad", puesto que parecieran postular el reemplazo de una forma por otra, y como hemos podido ver, no se trata de un reemplazo, sino de una mejor combinación de ambas formas. DE LA Oliva Prólogo en: PALOMO (2008) p. 2.
} 


\section{La concreción de una opción formal en la estructura del procedimiento: la combinación entre la oralidad y la escritura}

\section{Estructura del nuevo juicio ordinario}

En el Proyecto la oralidad aumenta y se refuerza, es la forma predominante, pero al igual que ha ocurrido en los lugares donde la experiencia ha sido exitosa, no ha sido por la asunción de alguna moda o por imponerlo así cierta visión doctrinaria e ideológica de lo que debe ser la modernidad procesal. En el Proyecto la oralidad aumenta teniendo a la vista un criterio que liga con la funcionalidad de cada etapa del proceso.

Así, en el juicio ordinario (arts. 230 y ss.) se contemplan actos de alegación escritos. En efecto, la demanda, la contestación de esta y la eventual reconvención son actos escritos (art. 7, inc. final). Con ello, evidentemente, se está buscando facilitar la exposición ordenada de los hechos y de los fundamentos jurídicos que en el marco de los procesos civiles han aumentado progresivamente su complejidad. Se impone, dentro de los requisitos de la demanda, la narración precisa de cada uno de los hechos que configuran la pretensión, además de tener que señalar el actor los medios de prueba con los cuales pretenden acreditarse, y el derecho en que se funda (art. 231 No 4). La forma escrita aparece como la más razonable, conveniente y segura de acuerdo al importante rol asignado primero a la demanda (como acto procesal iniciador del proceso civil, como en la determinación y delimitación del contenido del mismo) y luego a la contestación y eventual reconvención ${ }^{59}$. Idéntica precisión narrativa se impone al demandado respecto de los hechos que configuran las defensas y excepciones, además del deber de señalar los medios de prueba pertinentes con los cuales pretende acreditarlas y el derecho en que se fundan (art. 248 No 3). Debe valorarse positivamente que se haya esquivado fórmulas más simplistas que quisieren que ya la contestación fuere oral: el predominio de la oralidad en el proceso civil no impide ni puede impedir -razonablemente- recurrir a la forma escrita, al menos cada vez que sea necesario para el mejor desempeño de los objetivos de cada fase y acto procesal.

Aquellos que sostienen que la apuesta por la oralidad en el proceso civil solo "tolera" una demanda escrita, debiendo la respuesta del demandado traducirse necesariamente en una alegación oral, no hacen otra cosa que demostrar que sus planteamientos no consideran la realidad como un factor de importancia en la toma de decisiones. Se ignora la creciente complejidad de los actuales litigios civiles y se propone un cambio innecesario que, sin justificación, se opone a una cultura forense distinta y a un propósito buscado por el legislador: lograr claridad y precisión, desde la entrada al juicio, de las posiciones de las partes. De hecho, se impone la carga al demandado de pronunciarse categóricamente sobre la veracidad de los hechos alegados en la demanda por el actor: su silencio, así como sus respuestas ambiguas o evasivas se tendrán como admisión de esos hechos. Solo en circunstancias excepcionales (dice el

${ }^{59}$ La escrituración de esta fase es útil a fin de sostener lo que luego va a ser la fase oral. La escrituración de esta fase ofrece los cimientos sobre los cuales se desarrollará la siguiente fase oral. 
art. 249) podrá el tribunal no aplicar esta regla, atendiendo a razones debidamente fundadas expuestas para invocar que no se conoce o no se recuerda algún hecho o circunstancia alegadas por el demandante.

Mención destacada merece la consagración del deber para demandante y demandado de acompañar con la demanda y la contestación toda la prueba documental, además de ofrecer, con claridad y precisión, la prueba testimonial, pericial y otros medios de prueba (arts. 232, 233 y 250). Más allá de declaraciones genéricas, estos deberes son una manifestación concreta del principio de buena fe procesal, y a través de ellos se busca imponer a las partes mostrar, desde un inicio, sus principales cartas probatorias, evitando que una de las partes exponga a la contraria a sorpresas. Tiene el demandado, además, la carga de pronunciarse en su contestación (categóricamente) sobre la autenticidad, integridad y validez de los documentos que a ella se hubieren acompañado y cuya autoría le fuere atribuida: su silencio, así como sus respuestas ambiguas o evasivas se tendrán como admisión de la autenticidad, integridad y validez de los documentos.

En definitiva, la opción que se toma en el Proyecto parece adecuada toda vez que asume la mejor herramienta formal para que las partes puedan aportar al proceso, con pleno respeto a sus garantías procesales, los elementos necesarios para formar y delimitar con precisión el objeto del proceso, con todas las consecuencias que ello acarrea. A su vez, la escrituración en la respuesta del demandado permitirá avanzar con mayores grados de seguridad y legitimidad en la asimilación de los cambios procesales en que consiste la apuesta por mayores grados de oralidad en otras fases del proceso civil, cuestión nada de sencilla tras más de un siglo de monopolio de la escritura. En nada se está afectando el predominio de la oralidad en el proceso civil; la solución prevista implica solo entender las ventajas de una u otra forma dependiendo de la fase y acto procesal de que se trate. Todo esto, por cierto, no impide ni desaconseja que se prescinda de los escritos de réplica y dúplica para simplificar el procedimiento, lo que hace el Proyecto.

Superada la fase de alegaciones iniciales, el texto en comento apuesta claramente por la oralidad, la inmediación, la concentración y la publicidad (artículos 8-10). Es una combinación sobre la cual se ha escrito bastante (ya desde Chiovenda) y que básicamente se ha preocupado por destacar que la oralidad no solo se refiere a la característica predominantemente oral de los actos procesales, sino que implica otra serie de consecuencias (marcas) que trascienden este elemento puramente externo ${ }^{60}$. Entre estas mar-

\footnotetext{
60 Un reciente trabajo publicado en nuestro país así lo recuerda: "En realidad, la doctrina (brasileña e internacional) han tratado de demostrar que ese principio no se puede resumir, solamente, en la predominancia de la forma oral en la práctica de los actos procesales. De hecho, aunque ese elemento sea el más evidente de la caracterización del principio de la oralidad, su incidencia debe hacer nacer otras características, que son, generalmente, más importantes para la formación de un proceso efectivo, tempestivo y adecuado". En efecto, pensar en la oralidad-inmediación es pensar en un complejo de sub-principios que deben estar presentes cuando se examina un proceso oral. Cuando se piensa en proceso oral se pretende el contacto directo del magistrado con las partes y con la prueba del proceso, a fin de permitir la solución más adecuada y depuración más precisa de los hechos de la causa. Por ello, examinar la oralidad bajo el
} 
cas se deben contar la inmediación, la concentración y la publicidad del enjuiciamiento cuya interacción da forma a lo que por un modelo procesal oral se debe entender ${ }^{61}$.

Esta interacción se visualiza, en primer término, en la audiencia preliminar-de un contenido complejo ${ }^{62}$, y en segundo término, en la audiencia de juicio, en donde se practican las pruebas, se formulan -oralmente- las conclusiones sobre la misma ${ }^{63}$ y (decisión doctrinaria, y escasamente realista a nuestro parecer) dónde se pretende que se comunique de inmediato el veredicto (indicando someramente los principales fundamentos tomados en consideración) ${ }^{64}$. La sentencia definitiva deberá ser pronunciada por

prisma también de la inmediación, es reconocer que el proceso, al mismo tiempo que se desarrolla predominantemente por la vía oral, debe observar los principios de la convicción racional del juez, de la inmediatez, de la publicidad, de la concentración y del incremento de los poderes instructores del juez, además de tantos otros que son consecuencia de los mismos. "Se trata, por lo tanto, de un enfoque mucho más complejo y profundo, que exige una amplia meditación sobre el funcionamiento del proceso en examen. Por otro lado, estamos frente a un nuevo enfoque, ya que la simple oralidad, vista como forma de desarrollo del acto procesal, en sí misma, es insuficiente para permitir un criterio seguro, capaz de demostrar la adecuación o no del sistema procesal para la tutela de los derechos”. CRUZ (2008).

${ }^{61}$ Bien se ha dicho: "Deben quedar ya en el pasado los debates acerca de cuáles principios deben regir el proceso moderno, ya que existen sobre el tema amplias coincidencias. Ahora debemos profundizar sobre los mecanismos que la ley debe prever para que los principios procesales dejen de ser meros postulados programáticos y se transformen en herramientas decisivas para que el proceso haga efectivos los derechos sustanciales". PEREIRA (2003) p.1.

${ }^{62}$ Entre las funciones más importantes que se le asignan a esta audiencia está la posibilidad de que lleguen a un acuerdo las partes, el saneamiento de todos los obstáculos procesales que pueden impedir entrar en la decisión de fondo, la fijación definitiva de los hechos controvertidos a probar y la determinación de las pruebas a practicar.

63 Los actuales escritos de observaciones a la prueba son reemplazados por la formulación oral de conclusiones en la audiencia de juicio (art. 308). "Formulación de conclusiones. Una vez rendida la prueba en la audiencia de juicio, las partes formularán, oralmente y en forma breve, dentro del tiempo que les indique el Tribunal, las observaciones que les merezca la prueba, así como sus conclusiones, de un modo preciso y concreto, con derecho a replicar respecto de las conclusiones argumentadas por las demás. Si a juicio del juez hubiere puntos no suficientemente esclarecidos, podrá ordenar a las partes que los aclaren”.

64 "Excepcionalmente, cuando la audiencia de juicio se hubiere prolongado por más de dos días, o recayere sobre un punto de derecho de complejidad, cuya concurrencia fundamentará, podrá postergar la decisión del caso hasta el quinto día hábil... El juez podrá diferir la redacción del fallo hasta por un plazo de cinco días contados desde la fecha de comunicación de su decisión, ampliables por otros cinco días por razones fundadas, fijando la fecha en que tendrá lugar la lectura de la sentencia, la que podrá efectuarse de manera resumida, con solo las partes que asistan...” (art. 309). Consideramos que esta es una regulación que debe revisarse al ser incompatible con la mayor complejidad y dificultad que entrañan las causas civiles, de lo contrario se puede caer fácilmente o en la superficialidad o en la transgresión sistemática de la regla. El plazo para dictar sentencia debe ser un plazo que -con realismo, sin un excesivo celo doctrinarista y teniendo presente que la prueba más relevante en materia civil es la documental- permita al juez fallar con la frescura del conocimiento de causa. En el caso español este plazo es de veinte días (superior al establecido por la LEC derogada, pero inferior al que en la práctica se tomaban los jueces para fallar) respecto del cual en la Exposición de Motivos se dice que no se trata de un plazo que pueda considerarse, en sí mismo, excesivamente breve, pero sí razonable y de posible cumplimiento, porque es de tener en cuenta - se agrega- que la estructura nueva de procesos ordinarios comporta el que los jueces tengan ya un importante conocimiento de los asuntos y no hayan de estudiarlos o reestudiarlos al final, examinando una a una las diligencias de prueba llevadas a cabo por separado, así como las alegaciones iniciales de las partes y sus pretensiones, que, desde su admisión, frecuentemente no volvieron a considerar. En contra de la existencia de plazos que permitan a los jueces diferir la dictación de las sentencias, véase: DUCE et al. (2008) p. 68. 
el mismo juez ante el cual se hubiere realizado la audiencia de juicio ${ }^{65}$. Si el juez que presidió la audiencia de juicio no pudiere dictar sentencia, aquélla deberá celebrarse nuevamente (art. 309), disposición que es coherente con la inmediación judicial que se busca fortalecer de manera efectiva ${ }^{66}$.

La audiencia preliminar contempla, al igual que acontece ya en otros modelos predominantemente orales existentes en el derecho extranjero, las trascendentales funciones de conciliación, saneamiento de los defectos procesales, delimitación definitiva del objeto procesal y determinación de las pruebas que podrán ser practicadas en la audiencia de juicio ${ }^{67}$. De lograrse la conciliación entre las partes o no pudiéndose subsanar (o no habiéndose subsanado) los defectos procesales, esta audiencia habrá de servir para evitar seguir todo el proceso hasta el final. En las demás hipótesis, esta audiencia sirve para preparar el verdadero juicio en el que las partes habrán de probar sus alegaciones y llevar a cabo sus conclusiones que permitirán al juez dictar sentencia de fondo ${ }^{68}$.

Se ha estimado que la reforma debe pasar por la apuesta hacia el predominio de la oralidad como guía formal de aquellas fases del proceso que siguen al planteamiento inicial del caso que, como recién se dijo, es razonable y conveniente que siga siendo por

${ }^{65}$ Se entiende perfectamente desde el momento en que el juez formará su convicción sobre la base de las alegaciones y pruebas que personalmente haya recibido (art. 65 inc. final).

${ }^{66} \mathrm{El}$ art. 66 impone que la fecha de las audiencias se fije con la mayor cercanía posible a efectos de procurar la continuidad del proceso y la identidad del titular del órgano jurisdiccional.

67 Sobre esta audiencia puede consultarse: ABEL, X. (2003): "La audiencia previa: entre el deseo y la realidad". Revista del Poder Judicial, N69; Alonso-Cuevillas, J. "La audiencia previa al juicio". En: Alonso-Cuevillas, J. (2000): Instituciones del nuevo proceso civil. Comentarios sistemáticos a la Ley 1/ 2000. (Barcelona, Ed. Difusión Jurídica, Volumen II); BAnacloche, J.; Gascón, F. "El tratamiento de las cuestiones procesales en la audiencia previa al juicio”. En: BANAClOCHE, J., GASCÓN, F., GUTIÉRREZ, A. y VALLINES, E. (2005): El tratamiento de las cuestiones procesales y la audiencia previa al juicio en la Ley de Enjuiciamiento Civil. (Madrid, Ed. Thomson-Civitas); DE LA OlIVA, A. "Génesis de la audiencia previa en el juicio ordinario de la Ley de Enjuiciamiento Civil 1/2000”. En: BANAClOCHE, J. y otros (2005); FAIRÉN, V. "La audiencia previa al juicio de la Ley de Enjuiciamiento Civil del 7/1/2000". En: GómeZ, J.L. (2003). La aplicación práctica de la Ley de Enjuiciamiento Civil de 2000. (Valencia, Ed. Tirant lo Blanch); González, F. (2000) "La audiencia previa en el juicio ordinario de la Ley 1/2000, de 7 de enero", Revista Tribunales de Justicia, No 10; Guimaraes Ribeiro, D. (2001) "Audiencia preliminar y oralidad en el Derecho brasileño", Revista Justicia, Nº 2-4.

68 Sin perjuicio de lo dicho en cuanto a la función probatoria de la audiencia preliminar (que dice relación básicamente con la proposición, admisión y exclusión de pruebas), el art. 267 contempla dentro de los contenidos de la audiencia la recepción anticipada de prueba: "Recibir la prueba anticipada que sea necesaria rendir en ese momento". Se sigue en este punto al Código Modelo (art. 301), que autoriza a recibir en esta audiencia los medios de prueba que estén disponibles en ese momento. Lo que se está autorizando es que las pruebas tengan lugar en audiencias distintas, en la audiencia preliminar y en la audiencia de juicio, con lo que las ventajas de la inmediación y la concentración en la actividad probatoria pueden resentirse. En este caso compartimos la opinión negativa que algunos tienen de este proyecto de norma. La razón fundamental es que si bien es tolerable (desde un punto de vista realista) que el juez falle tras quince o veinte días de haber presenciado la práctica probatoria, no es razonable ni coherente con la inmediación judicial que los jueces fallen con el recuerdo de lo acontecido en una audiencia producida dos, tres o cuatro meses atrás. Si la decisión sobre los hechos se toma meses después de practicadas las pruebas la fuente de la decisión será un acta escrita y no la prueba oral. Nos referimos -claro está- a la hipótesis en que se práctica prueba en la audiencia preliminar y en la audiencia de juicio. Véase: DUCE et al. (2008) p. 70. 
escrito. En consecuencia, se apuesta por un proceso civil que tras los actos de alegación de las partes se basa en las reglas de oralidad y concentración procesal, esto es, se diseña un proceso que se construye desde el modelo por audiencias. El Proyecto la tendencia que se refleja en el Código Modelo y en la nueva LEC española.

Es conveniente que ambas actuaciones se desarrollen oralmente. Tratándose de la audiencia preliminar ${ }^{69}$, la oralidad junto con ser un factor de eficiencia ${ }^{70}$, debe permitir obtener los mejores provechos de los contenidos y finalidades asignados a la misma que, anotamos, son variados y superan la labor de saneamiento procesal (art. 254). Destacamos especialmente la mayor flexibilidad que permite la oralidad en esta actuación. El diálogo previo oral -en unidad de acto- junto con ser más natural que el mero intercambio de escritos, debe evitar la utilización puramente formalista de esta fase del proceso (como dice el conocido dicho popular: "el papel aguanta todo") y debe facilitar la interrogación por parte del juez y la respuesta inmediata por parte de los abogados, permitiendo una acabada ilustración temprana del asunto. Pero no conviene caer en excesos. Debe mantenerse la vista en las posibilidades que manifiesta la realidad. Debe diseñarse un modelo de audiencia formalmente dominado por la oralidad y sus formas conexas, pero adecuadamente equilibrado por la escritura en aquellos casos en donde esta regla resulte necesaria para la mejor resolución de los asuntos ${ }^{71}$. Así, determinadas cuestiones suscitadas en la audiencia deberían poder resolverse por escrito y una vez ya terminada la audiencia (la concentración, al igual que la oralidad, no debe ser entendida como dogma absoluto).

Ubicado en el haber de esta configuración oral de la audiencia preliminar debe contabilizarse el temprano contacto del juez con la causa. Destacable resulta la inmediación judicial que regirá el acto, situación que debe ser decisiva a la hora de transitar desde un proceso sobre escritos a uno sobre personas, y debe repercutir muy favorablemente en la calidad de los resultados que se obtengan de esta fase del proceso. Esta participación inicial del juez con la causa debe ser un sello distintivo del nuevo modelo, desde el momento en que este esquema fuerza al juez a abandonar -ya de entrada- una tradicional distancia impuesta y hasta fomentada por el actual sistema ${ }^{72}$.

\footnotetext{
69 GASCÓn y PALOMO (2007).

70 Bien se ha dicho por Taruffo que en una vista de tanta importancia la oralidad cumple un papel fundamental, y resulta un factor de eficiencia indispensable y sustancial: si todas las actividades que se ejecutan en la audiencia se llevasen a cabo mediante escritos y órdenes, se requeriría un gran volumen de tiempo. TARUFFO (2008).

${ }^{71}$ EL PCPC no muestra mucha flexibilidad en este punto. Señala entre sus principios básicos a la oralidad y agrega que el proceso de deberá desarrollar en audiencias orales, debiendo las resoluciones (todas) ser dictadas y fundamentadas verbalmente por el Tribunal en la audiencia (art. 7-64).

72 Estas labores de preparación del juicio, aunque sean heterogéneas, pueden concentrarse en un solo acto, al que, por eso mismo, le conviene la forma oral: se fuerza con ello un primer contacto directo del tribunal con el proceso y su objeto, al tiempo que se asegura una efectiva delimitación del objeto de la controversia y una acertada decisión acerca de las pruebas que han de admitirse y aquellas que, en cambio, en tanto que inútiles y/o impertinentes, deben rechazarse. Estos son los postulados sobre los que el legislador español construyó en la LEC 1/2000 la institución de la audiencia previa al juicio como pieza clave del desarrollo procedimental del juicio ordinario. Un correcto diseño legal, que asegura su efectiva celebración y un alto nivel de rigor y seriedad al abordar cada uno de sus contenidos, ha permitido que la realidad se haya
} 
Los importantes contenidos que se contemplan para esta audiencia así lo exigen. Juez, partes y abogados deben asistir y participar de manera muy activa y para ello deben estar preparados ${ }^{73}$. El modelo exige conductas distintas de parte de los jueces y de los abogados, exige abandonar esa pasividad tan característica del proceso vigente. Implica, entre otras cosas, un aumento de los poderes de dirección formal del juez ${ }^{74}$ que el PCPC en comento se ha preocupado de dejar establecidos ya en los primeros artículos al señalar que promovido el proceso y en cualquier estado del mismo, el juez deberá adoptar, de oficio, todas las medidas que considere pertinentes para su válido, eficaz y pronto desarrollo, de modo de evitar su paralización y conducirlo sin dilaciones indebidas a la justa solución del conflicto (art. 4).

Del otro lado, se contempla la audiencia de juicio, destinada fundamentalmente a la práctica concentrada de la prueba y a la formulación oral de las distintas conclusiones que merezca a las partes, todo siempre con la presencia del juez, quedando prohibida, bajo sanción de nulidad, la delegación de funciones (art. 65-260). La apuesta por la oralidad en esta fase del proceso es razonable y hasta necesaria. En efecto, si se conservara el esquema vigente del modelo escrito y desconcentrado a los efectos de la práctica de la prueba ningún avance real se lograría ${ }^{75}$. La práctica concentrada de las pruebas aparece como la única manera de rescatar esta actividad de la situación de desprestigio y descrédito en la cual suele encontrarse hoy en día nuestra realidad forense (pensamos aquí en la concreta suerte de la prueba testimonial o de la prueba de absolución de posiciones).

Tratándose del acto del juicio y su contenido fundamental, las ventajas y beneficios que aporta la oralidad son evidentes ${ }^{76}$. Oralidad, concentración e inmediación

adecuado a la previsión legislativa. De este modo, la audiencia previa está cumpliendo, de forma casi desapercibida, la función que tiene encomendada y se ha convertido así en uno de los elementos que han servido de punto de arranque para la efectiva reforma y mejora de la justicia civil española.

73 Se ha denunciado por algún autor que en el modelo español, en la práctica, sucede que en ocasiones la preparación por parte del juez no se realiza, sacrificándose tiempo y recursos. En esta línea (y seguramente teniendo a la vista la tendencia en otros países europeos) se ha dicho que quizás la oralidad en esta fase del proceso sea inoportuna. "La indebida práctica es, a veces, tan alarmantemente frecuente, que quizás haya que llegar a la conclusión de que supone un esfuerzo quizás innecesario el hecho de que el juez deba preparar concienzudamente tantas audiencias previas como tiene que celebrar a lo largo de la semana”. NiEva (2007) p. 112. Pero desde el otro lado bien se ha dicho que en los sistemas modernos la fase previa al juicio se ha convertido en la más importante del proceso, en esencia, debido a su capacidad para dar término al conflicto evitando el juicio y la sentencia, y en su defecto, para esclarecer, simplificar y determinar los extremos de hecho y de derecho en los que haya controversia. TARUFFO (2008).

${ }^{74}$ El modelo oral exige un nuevo papel del juez que, respetando la igualdad de las partes, y la naturaleza del proceso civil, se encuentre (como se ha ilustrado por alguna doctrina) "a pie de obra", especialmente comprometido en la obtención de una rápida solución del conflicto que separa a las partes y en dirigir el procedimiento desde sus inicios.

75 De hecho, la experiencia de otros países así lo demuestra. Así por ejemplo ocurrió en España con la fracasada reforma de la Ley de Reforma Urgente de 1984, ya comentada antes en este trabajo.

76 La forma escrita (y sus reglas asociadas), en cambio, no es buena compañera cuando hablamos de la práctica de las pruebas. No se trata solamente de una apreciación formulada desde la teoría; la práctica -lamentablemente- ha demostrado cuán cierto es este juicio. Y no es una buena compañera, sencillamente, porque un proceso tan desbordadamente escrito como el recogido en el CPC chileno apunta claramente en la dirección contraria a la que aparece como más razonable y conveniente tratándose de la actividad probatoria. A lo explicado antes en este trabajo nos remitimos. 
judicial son reglas que potencian la actividad probatoria, la revalorizan, ganando en seriedad y calidad desde el momento en que se fortalece el juicio de hecho con un juez que va a estar efectivamente presente en la práctica de las pruebas. Esta combinación de reglas debe estar al servicio de una práctica probatoria mucho más flexible y espontánea que la actual. La nueva regulación que se propone de la prueba testimonial y de declaración de parte son claros ejemplos de lo que decimos, se favorece la espontaneidad de las preguntas y las respuestas y se evitan los rigorismos formales no justificados que constituyen limitaciones probatorias (art. 305).

La apuesta legislativa por la práctica oral y concentrada de las pruebas, además de configurar la opción procesal más racional, conveniente y apropiada tratándose de estas actuaciones procesales probatorias ${ }^{77}$, terminará de afirmar una nueva concepción del proceso civil en donde exista un juez siempre visible ${ }^{78}$, muy atento a las pruebas que se practiquen en su insustituible presencia, precisamente sobre las cuales sostendrá su decisión final. Se recuperará de este modo la importancia en parte perdida del juicio de hecho o fáctico.

\section{Cuidado con el diseño definitivo del procedimiento sumario}

En lo que se refiere a la propuesta relativa a la regulación del procedimiento sumario (arts. 312 y ss.), cabe señalar que en un comienzo el ACPC no contempló contestación de la demanda por escrito y estableció que tras una demanda escrita se pasara luego a la realización de una sola audiencia (sumaria) en la cual se busca cumplir con los objetivos previstos para la audiencia preliminar y de juicio ${ }^{79}$. De algún modo, se quería que toda la actividad que se prevé para la fase de audiencia preliminar del juicio ordinario, en el juicio sumario se desarrolle en la propia audiencia, que debiera hacer -en su primera parte- las veces de audiencia preliminar ${ }^{80}$.

En lo relativo al objeto de este trabajo, en el ACPC se quiso reforzar especialmente la oralidad en comparación con lo previsto para el juicio ordinario: la contestación del demandado se debía producir (en este plan) en la audiencia, oralmente, una vez que el actor haya completado su demanda al inicio de la misma. Esa era la fórmula prevista en el ACPC.

\footnotetext{
77 La oralidad y sus formas conexas, la inmediación, la concentración y la publicidad general, se presentan como especialmente apropiadas para sacar el mejor provecho a la actividad probatoria.

78 El "milagro" de la oralidad no se agota en hacer visible al juez. Bien se ha señalado que también hace visible a los abogados, que bajo este sistema se ven obligados, por la trascendencia de las actuaciones involucradas, a redescubrir el foro en los asuntos civiles.

79 El iter del juicio sumario comprendía: a) Presentación de la demanda sucinta; b) Examen de oficio por el tribunal de los presupuestos procesales y los requisitos de la demanda legalmente exigidos y admisión de la misma si fuere el caso; c) Citación de las partes a la audiencia; d) Actuaciones posibles previas a la audiencia (por ej. una eventual reconvención); e) La audiencia; f) La sentencia.

${ }^{80}$ Así, la primera parte de esa audiencia tiene como cometido poner de manifiesto los defectos procesales que impidan una resolución sobre el fondo...; despejado aquello, la audiencia continúa para que las partes fijen los hechos y propongan prueba. Después de resolver las cuestiones procesales, fijados los hechos controvertidos y determinada la prueba a practicar, la audiencia continúa en unidad de acto para el enjuiciamiento de la cuestión debatida por las partes, con la práctica de la prueba (art. 317).
} 
Pues bien, esta modalidad de diseño del juicio sumario coincide con la prevista para el juicio "verbal" en la normativa española. En su momento fuimos críticos de la reproducción entre nosotros de esta fórmula. Al respecto, explicando nuestra posición crítica, pedíamos tener a la vista que el Proyecto de LEC española preveía dos modalidades de juicio verbal, una de ellas para los asuntos más simples o sencillos ya sea por su escasa cuantía o complejidad (en el cual tras la demanda escrita sucinta debía citarse a ambas partes al acto de la vista) y otra destinada para asuntos menos sencillos, bien por tener cuantía superior (aunque no de la envergadura de las cuantías propias del juicio ordinario) o tener una complejidad mayor, en donde después de la demanda escrita semejante a la prevista para el juicio ordinario, se preveía una eventual contestación también por escrito del demandado, para después dar paso a la vista oral. El trámite parlamentario no dio luz verde en España a esta doble modalidad de juicio y optó por configurar como única modalidad de juicio verbal a aquella que más decididamente apostaba por la oralidad y la concentración.

El punto es que si se estaba tomando como referencia el juicio verbal español, debían tenerse a vista también las dificultades que ha aparejado -en la práctica- la apuesta por la modalidad única más comprometida con la oralidad. En efecto, la alternativa que se planteaba en el proyecto de LEC hubiese permitido que en aquellos casos no tan sencillos existiera la posibilidad de fijar antes de la audiencia las alegaciones y pretensiones de las partes. Al optarse por un único diseño más oral y concentrado (sin contestación por escrito) el juicio verbal español viene presentando un importante problema que se traduce justamente en la ausencia de una fijación con carácter previo a la vista de las alegaciones y pretensiones de ambas partes, lo que deriva en frecuentes suspensiones y aplazamientos ${ }^{81}$. Y bien se sabe que el abuso en las suspensiones y los aplazamientos son un verdadero cáncer (uno de los peores enemigos) de los procesos que tienden hacia mayores grados de oralidad ${ }^{82}$. Tanto así que la concentración procesal perseguida en esta clase de modelo procesal puede quedar en letra muerta ${ }^{83}$.

${ }^{81}$ GASCÓN (2008) p. 185.

82 A propósito de este punto, creemos que los artículos 11, 105 y 276 resultan insuficientes si lo que se quiere es evitar una propagación de suspensiones. El nuevo CPC debe hacerse cargo con mayor rigor y detalles de los supuestos en que son posibles las suspensiones e interrupciones. El recurso a la imposición de multas frente a actuaciones de los abogados, litigantes, peritos o testigos no debiera desecharse si se quiere evitar el daño que producen las suspensiones. Debe tomarse nota de la experiencia acumulada ya en materia de procesos de familia. Debe recogerse una regulación que evite al máximo que se suspendan las audiencias.

${ }^{83}$ El profesor Gascón explica bien el problema a partir de la referencia España y Francia. “Debe ponerse de relieve la frecuencia con la que los legisladores nacionales incurren en un error de base: a la hora de diseñar modelos procedimentales, lo habitual es que las mayores dosis -y los excesos- en la oralidad se reserven para los procesos que tienen una menor cuantía. Esto es lo que sucede en España con el juicio verbal (hasta 3.000 euros) o lo que ocurre en Francia con los procesos ante el tribunal d'instance y el juge de proximité. Cuando los intereses económicos en juego son elevados, el legislador considera razonable que el proceso tenga un cierto soporte escrito, al menos en sus momentos iniciales; en cambio, los riesgos de una oralidad completa se asumen únicamente cuando el interés económico en juego es más reducido. Ahora bien, sobre todo en el ámbito civil y mercantil, es absolutamente incorrecto identificar la escasa cuantía de un litigio con una pretendida sencillez fáctica o con una eventual simplicidad de las cuestiones jurídicas que han de 
Afortunadamente, el texto del PCPC enmienda el rumbo en este tema y contempla una contestación escrita, antes de la audiencia sumaria (art. 316), con lo cual se evitan los problemas antes descritos.

Añadidamente, dicho ACPC aludía a una demanda sucinta. En ella debían consignarse los datos y circunstancias de la identificación del actor y del demandado y el o los domicilios en que pueden ser citados, fijándose con claridad lo que se pidiera ${ }^{84}$. Por tanto, se trataba de una demanda que no requería contener todos los fundamentos fácticos y jurídicos de la tutela jurisdiccional pedida. El PCPC elimina esta alusión y exige que el juicio sumario comience por demanda escrita, la que deberá cumplir los requisitos del art. 231 previstos para la demanda en el juicio ordinario, y deberá acompañarse también toda la prueba documental de que se disponga y se deberán ofrecer todos los demás medios de prueba de que pretenda valerse el actor, bajo sanción de no poder ofrecerlos ni rendirlos con posterioridad. A la valoración efectuada antes sobre esta regla remitimos al lector.

Aun con este cambio, tratándose del juicio sumario, se está frente a un diseño mucho más concentrado que evita la doble comparecencia prevista para el juicio ordinario. Todo indica que la voluntas es consagrar un procedimiento más sencillo, abreviado y rápido que se ajuste más a la naturaleza y cuantía muchos litigios. Así se ha entendido por quienes elaboraron el PCPC que junto al juicio ordinario contemplan un juicio sumario que tendría aplicación para las demandas cuya cuantía no exceda de 250 UTM.

Se impone la concentración, tras las alegaciones escritas de las partes, en un solo acto, de prácticamente todas las actuaciones del proceso. El juicio sumario que se propone gira en torno a la audiencia sumaria: se advierte que salvo la demanda, la contestación y la sentencia todas las demás actuaciones tienen lugar en ella de modo oral y concentrado. De hecho, el juez debe resolver de inmediato, indicando los fundamentos principales de su decisión. En caso que la audiencia se hubiere prolongado por más de dos días, el juez podrá postergar la decisión del caso, hasta el día siguiente hábil, citando de inmediato a las partes a la audiencia respectiva. Dentro de los diez días siguientes a la

ser enjuiciadas en el proceso, elementos estos - la sencillez fáctica o la simplicidad jurídica de un caso- que son los que, en puridad, justifican un cauce procesal más liviano, que puede traducirse en la previsión legal de un procedimiento total o casi totalmente oral”. GASCÓN (2008) p. 185. En la misma línea conviene leer al profesor De la Oliva: "Se ha dicho muy acertadamente que no se puede construir los procesos en abstracto, en la ley, como si se pensase que cada juez y cada abogado tienen solo uno... El diseño más simple de un proceso oral puede verse contrarrestado con largas listas de espera para la celebración de los juicios o con una baja calidad de los pronunciamientos jurisdiccionales, en especial si en el ámbito de la magistratura se asocia inconscientemente la oralidad con una pretendida capacidad para dictar sentencias acertadas sin necesidad de un estudio detenido y atento de cada caso. Y entre la lentitud y la justicia del cadí, parece preferible la primera, salvo que solo se atienda a las estadísticas". Véase: DE LA OLIVA y otros (2003) p. 56.

${ }^{84} \mathrm{Si}$ bien se señala que el juicio sumario principiará por demanda sucinta del actor, lo cierto es que el texto no ha prohibido que el demandante opte por presentar demanda completa en los términos exigidos en el juicio ordinario. Cuando opte por este camino el actor, en la audiencia solo tendrá que ratificar la demanda (art. 390). Cuando no lo haga, la fase "alegatoria" quedará dividida entre la presentación de la demanda sucinta (por escrito) y su posterior complementación en la audiencia a través de la exposición oral por el actor de los fundamentos fácticos y jurídicos de lo que se pide. 
fecha en que se dio a conocer la decisión, el juez deberá entregar la redacción de la sentencia, la cual, en forma oral y resumida, dará a conocer a las partes en audiencia especialmente fijada al efecto, plazo que podrá ser ampliado hasta por cinco días por resolución fundada (art. 318).

\section{APERTURA Y LIBERTAD PROBATORIA DE LA MANO DE LA MAYOR FUERZA QUE TOMA LA ORALIDAD}

\section{Consolidación de una apertura de los medios de prueba admisibles}

Bien conocidas son las manifestaciones del sistema de prueba legal ${ }^{85}$. Pues bien, el vigente sistema -no sin cierta coherencia hacia la configuración de un proceso desbordadamente escriturado (que resulta como ya se ha dicho altamente mediatizado) - consagra un listado cerrado de medios de prueba.

La nueva normativa debe afrontar también esta cuestión. En efecto, de la mano con el modelo que recoge, el Código (art. 341) consagra un listado de medios de pruebas que las partes pueden utilizar para lograr acreditar, a los efectos del proceso, las afirmaciones fácticas realizadas. El Código Civil (art. 1698 inc. 20) también consagra una lista que, con pequeñas variaciones, señala los medios de prueba admisibles. Como sea, en el modelo vigente es la ley la que determina -taxativamente- los medios de prueba $^{86}$. Conforme a este esquema, más allá de los esfuerzos de interpretación que se han realizado por la doctrina y los tribunales, los modernos mecanismos de reproducción de la imagen o el sonido han experimentado una serie de problemas para ser admitidos. Es necesario, a fin de evitar las dificultades que hasta ahora han experimentado los esfuerzos de la práctica forense, que la nueva normativa zanje con libertad, flexibilidad y apertura este tema. La taxatividad en comento es claramente incompatible con una sociedad tecnologizada que experimenta avances tecnológicos a una velocidad siempre superior a aquella que puede poseer el legislador para encuadrarla dentro de una norma rígida ${ }^{87}$.

\footnotetext{
85 Es el legislador quien determina los medios de prueba admisibles y es el mismo legislador quien anticipadamente establece la valoración que a cada medio de prueba habrá de dar el juez.

${ }^{86}$ No podemos abordar aquí -por limitaciones de espacio- la cuestión de la mayor o menor flexibilidad y creatividad con que se puede afrontar este listado legal. De hecho, como muy ilustrativamente ha explicado el profesor Gonzalo Cortez, se ha venido imponiendo poco a poco una solución más aperturista, primero, de la mano de la amplitud de la constitucionalización del derecho a la prueba, como contenido de la garantía del debido proceso, que impone -entre otras cosas- que la interpretación de las normas relativa a la admisión de los medios de prueba se oriente siempre hacia la efectividad del derecho de las partes a probar sus aseveraciones fácticas que son la base de sus pretensiones y defensas. En segundo lugar, esta solución aperturista ha encontrado sustento en la distinción entre fuentes y medios de prueba que ya se difunde entre nosotros. Con todo, los problemas (más prácticos) han estado a la hora de incorporar al proceso estos modernos mecanismos. En punto a esta dificultad, existen opiniones en el sentido de utilizar el cauce procedimental más idóneo, por ejemplo, tratándose de fotografías o radiografías, estas podrían ingresar al proceso a través del medio de prueba documental. Una excelente explicación de la distinción entre fuentes y medios de prueba véase en: MENESES (2008).

${ }^{87}$ Maturana (2002).
} 
El texto propuesto opta con claridad, al igual que ha venido sucediendo con las reformas procesales anteriores, por la libertad de prueba por lo que todos los hechos $y$ circunstancias pertinentes para la adecuada solución del conflicto sometido al conocimiento del juez podrán ser probados por cualquier medio obtenido, ofrecido e incorporado al proceso en conformidad a la ley (art. 260) ${ }^{88}$. Las partes tendrán libertad para presentar cualquier medio de prueba con tal de que sea pertinente.

\section{Un sistema de valoración libre conforme a las reglas de la sana critica}

Otra de las marcas, se dice ya desde Chiovenda, que vienen determinadas por la opción hacia la oralidad en la Justicia civil se encuentra en el sistema de valoración de las pruebas que se recoge ${ }^{89}$. En efecto, la opción del PCPC se dirige a consagrar un sistema de valoración de las pruebas más coherente con la nueva estructura oral, concentrada y propiciadora del contacto directo entre el juez, las partes y sus respectivos medios de prueba.

Ahora bien, como bien se ha dicho por la mejor doctrina, hay que acercarse a este tema sin el maniqueísmo habitual que parte de imputar a un sistema, el de la prueba legal, todas las aberraciones imaginables en el mundo de lo jurídico, y al otro, el de la prueba libre, "todas las perfecciones de este mundo y de los próximos" ${ }^{0}$. Ejemplos abundan en este sentido91.

La valoración legal no tiene por qué desaparecer totalmente, a menos que suscribamos acríticamente el discurso de la concepción publicista del proceso civil que propugna el aumento de los poderes del juez y señala que las normas legales de valoración supondrían una limitación de estos, razón por la cual estas deberían desaparecer ${ }^{92}$. En efecto, la prueba legal bien entendida no tiene relación ni con la prueba ordálica ni con la prueba apriorística como se ha pretendido erradamente por algunos; lo decisivo en ella son las máximas de la experiencia ${ }^{93}$, por lo que las reglas legales de valoración no tienen por qué ser absurdas ni producto de la arbitrariedad si responden a verdaderas máximas de la experiencia. Al contrario, bien concebidas, estas reglas -de existir- en-

${ }^{88}$ Esta propuesta de norma se debe complementar con la del art. 302 que señala: "Podrán admitirse como pruebas cualquier otro medio o sistema de reproducción de la imagen, el sonido o la escritura, apto para producir fe, independiente de su soporte. El juez determinará la forma de su incorporación al procedimiento, adecuándola en lo posible, al medio de prueba más análogo".

89 Estableció la relación entre oralidad, inmediación y valoración libre de las pruebas. CHIOVENDA.

${ }^{90}$ Montero (2008) p. 38.

91 Se dijo: "la prueba legal es una institución periclitada, en vías de desaparición”. SENTís (1978) pp. 125 y 126. En la misma línea: "Quizá en el aspecto probatorio es en donde puede encontrarse la fase más importante del progreso de los sistemas para la administración de Justicia pues los sistemas de valoración reflejan la civilización y la barbarie”. Devis (1972) p. 42.

92 Montero (2008) p. 38.

93 Se les ha definido así: "Son definiciones o juicios hipotéticos de contenido general, desligadas de los hechos concretos que se juzgan en el proceso, procedentes de la experiencia, pero independientes de los casos particulares de cuya observación se han deducido y que, por encima de esos casos, pretenden tener validez para otros nuevos". STEIN (1973) p. 22. 
cuentran justificación en la seguridad, certeza y normalidad jurídica como elemento de garantía de las partes en el proceso ${ }^{94}$.

En esta perspectiva, el establecimiento por el legislador de algunas reglas legales de valoración no debiera demonizarse. Por ejemplo, como ocurre en la nueva LEC española, cuando se establece que el documento público hace prueba, está el legislador dándole al juez un mandato para el caso de que en un proceso se presente esa prueba, pero antes también estará creando seguridad jurídica en el terreno de las relaciones de derecho material ${ }^{95}$.

Los jueces, según el Proyecto, apreciarán la prueba de acuerdo a las reglas de la sana crítica. La explicación de lo que aquello significa se encuentra en la misma norma propuesta (art. 266) ${ }^{96}$, destacándose la estrecha comunión entre esta forma de valoración de las pruebas con la imposición (reforzada) del deber de hacerse cargo en la fundamentación de la sentencia de toda la prueba rendida, incluso la desestimada indicando las razones que tuvo para ello (arts. 189 y 310 No 4) ${ }^{97}$. Por tanto, así como la prueba legal no puede entenderse hoy en relación a las pruebas ordálicas y apriorística, la valoración libre según las reglas de la sana crítica no puede vincularse a la valoración según la íntima convicción. La valoración según las reglas de la sana crítica conduce a una valoración razonada, motivada y responsable, debiendo el juez precisar las máximas de la experiencia utilizadas y desde las que ha llegado a su conclusión probatoria ${ }^{98}$.

Lo importante es que frente a otros ordenamientos en los que como reacción contra la prueba legal se pone el acento en la libertad del juez (como sucede cuando se habla de libre convencimiento), el sistema propuesto (sostenido en la sana crítica) pone el énfasis en la racionalidad que ha de estar en la base de la valoración ${ }^{99}$. Bien se ha

\footnotetext{
${ }^{94}$ Montero, haciendo referencia a lo que finalmente consagró la nueva LEC, señala: "Constituye máxima de la experiencia perfectamente razonable la de que debe ser creída la parte que reconoce hechos personales que la perjudican, la de que en las escrituras públicas los notarios hacen constar datos objetivos veraces, como la fecha verdadera en que se otorgan, y que reflejan con exactitud lo que dicen los contratantes, la de que cuando la parte reconoce un documento privado en lo que le perjudica también debería ser creída". MONTERO (2008) p. 57.

95 Montero (2008) p. 45. "Si dos personas deciden otorgar en escritura pública un contrato, pueden estar pensando en una doble seguridad jurídica: 1) Por un lado están dando certeza a sus relaciones jurídico materiales, pues evitan dudas sobre el contenido efectivo de esas relaciones, 2) Por otro, están preordenando la certeza probatoria, pues la regla legal que se contiene en la mayor parte de los Ordenamientos jurídicos está preconfigurado la valoración futura, dado que el juez no podrá desconocer el valor de la escritura pública. De este modo resulta que, primero, las partes de la relación material pueden incluso evitar que sea necesario el proceso, pues las partes conocen de antemano cuál será el resultado probatorio, pero si llegan a ese proceso impiden conclusiones probatorias absurdas, siempre posibles en manos de los jueces".

${ }^{96}$ Se aprecia una innecesaria repetición de ideas en estos artículos, lo que debiera mejorarse.

${ }^{97} \mathrm{La}$ motivación de la sentencia se convierte entonces en una forma de control de la sana crítica. "La prudente apreciación de las pruebas por parte del juez en ningún caso es sinónimo de irracionalidad o arbitrariedad, sino que por el contrario, en los sistemas de la prueba racional la valoración de las pruebas debe someterse a diversas reglas que garantizan su racionalidad, razonabilidad, coherencia y corrección lógica" (Maturana). Este control es justamente lo que diferencia al sistema de sana crítica con el sistema de la libre convicción.

98 MONTERo (2008) p. 48.

99 Montero (2008) p. 48.
} 
dicho que las reglas de la sana crítica son máximas de experiencia judiciales, que si bien no están codificadas, sí deben hacerse constar en la motivación de la sentencia, excluyendo de este modo la discrecionalidad a través de la posibilitación del control de la decisión por la vía los recursos ${ }^{100}$.

Las únicas reglas legales que se establecen son las contenidas en el art. 266 incisos 2, 3 y 4. Dicen relación con la valoración de la prueba respecto del acto o contrato solemne (que se prueba por su solemnidad), y la presunción de simplemente legal y derecho, esta última la cual conduce a la exclusión de prueba respecto del hecho presumido. De acuerdo a lo dicho antes (en relación con el sentido que cabe darle hoy a las reglas legales de valoración y su importancia para la obtención de la seguridad jurídica), no vemos problema en ser más precisos en la regulación de las reglas legales de valoración tratándose de la prueba documental y la prueba de interrogatorio de partes que hacen referencia a máximas de la experiencia indubitadas. Se gana en seguridad y certeza jurídica, y nada se sacrifica la esencia del modelo de valoración que se centra, como ya se apuntó, en las máximas de la experiencia.

\section{EL PAPEL DEL JUEZ EN EL NUEVO MODELO}

Ya hemos destacado suficientemente que el modelo procesal que se propone ha tenido en otros países el mérito de recuperar la figura del juez que, bajo un modelo como el actual, está reservada casi exclusivamente para el momento de la sentencia. Como han dicho: Su Señoría solo al final del trayecto procesal. Consecuencia positiva de todo este cambio debiera ser el término del juez "invisible".

La inmediación judicial, si se termina aprobando la implementación de este modelo, dejará de ser letra muerta como ocurre en la actualidad (basta aludir a la práctica de la prueba testimonial y confesional para dar cuenta de este fenómeno) ${ }^{101}$. Aparte de las sanciones (procesales y funcionarias) que se imponen, se consagra la necesidad de grabar las audiencias, lo que forzará la realidad de la inmediación, tal y como ha acontecido en otros lugares.

La estructura misma que se propone sugiere que cada asunto va a poder ser mejor seguido por el juez desde su inicio ${ }^{102}$. Se trata, más allá de las críticas que puedan

\footnotetext{
100 Montero (2008) p. 50.

101 Sobre las ventajas de la inmediación judicial coincide la doctrina. Se ha señalado: "Las ventajas de la inmediación son evidentes. No existe un instrumento tan poderoso para la búsqueda de la verdad en el proceso. El poder-deber del magistrado de escuchar y fundamentalmente dialogar con las partes, los letrados, los testigos y demás personas que actúen en el proceso le permite ponderar no solo las palabras, sino también -lo que es más importante- las reacciones y gestos, de fundamental importancia para apreciar la verdad o la mentira en una declaración”. PEREIRA (2003) p.2. Un análisis crítico, véase en: ANDRES (2003) pp. 57 y ss.

102 Aunque se han expuesto algunos inconvenientes a la luz de la experiencia práctica recogida en otros sistemas. Así se ha dicho: "Es ilusorio pensar que un juez atiende únicamente a un proceso, como perciben los ciudadanos en las películas cinematográficas, sino que lleva multitud de casos. Por ello, aunque esté presente en las vistas y tenga, por tanto, la máxima inmediación, es imposible que retenga en su memoria todos los datos que ha visto en cada proceso a la hora de dictar sentencia. Además, los asuntos que se ventilan no siempre son tan sencillos como para resolverlos en una audiencia...”. "... el hecho de que el juez tenga más de un caso pendiente -lo que prácticamente siempre sucederá-, provocará que en esa
} 
formularse o de los problemas que puedan detectarse, de un modelo más racional de trabajo. Desde luego que es un modelo más exigente para todos los involucrados ${ }^{103}$, pero esta mayor exigencia se compensa con la mejor posibilidad de arribar a sentencias más justas o, como lo dijéramos más arriba, con la mejor posibilidad que da el modelo de lograr una respuesta jurisdiccional de más calidad simplemente por el mayor y más cercano contacto del juez con las pruebas aportadas por las partes.

Sin embargo -ahora me refiero a una parte de la reforma que no genera tantos consensos- estamos convencidos de que la idea de la oralidad a la Justicia civil debe abrirse paso sin necesidad de desfigurar los principios sobre los cuales se levanta razonablemente un proceso civil, esto es, los principios dispositivo y de aportación de parte ${ }^{104}$, que como bien se sabe, encuentran su fundamento y origen en la naturaleza predominantemente privada o individual de los derechos e intereses en juego, lo que explica que el proceso se construya asignando a las partes un papel muy importante. Por ello, como no debe ser de otra forma, de las partes depende la existencia del proceso ${ }^{105}$, como también la determinación de su objeto ${ }^{106}$. Lo propio en cuanto a los concretos resulta-

misma mañana en la que se celebran las vistas, tenga, por ejemplo, 5 ó 6 vistas en el mejor de los casos. Por bien preparado que esté para todas ellas, es materialmente imposible que ni siquiera el más excelente de los jueces preste la misma atención en todas las comparecencias”. La fatiga o el afán de no retrasar las audiencias programadas puede llevarlo a caer en la tentación de cortar el uso de la palabra a los letrados o les inquiera directamente sobre lo que desea oír exclusivamente... lo que lo llevará a la precipitación y un conocimiento sesgado de la controversia. NiEVA (2007) p. 110.

103 Por ejemplo, los abogados no tienen demasiado tiempo para reaccionar debidamente a las alegaciones de la contraria. Se requiere que abogados y jueces se preparen. "Y es que cuando sucede que abogados poco experimentados acuden a las vistas, o incluso es el juez el que cuenta aún con poca experiencia, lo cierto es que las ventajas de la oralidad no se aprovechan o se aprovechan en menor medida”. NIEVA (2007) p. 111. Aunque este mismo autor puntualiza que lo mismo ocurre con la escritura: "Un abogado que redacte mejor tendrá ventaja sobre el que realice relatos más pobres”. La mayor preparación que se requiere también se destaca por Pereira: "La necesidad de la inmediación y de un papel activo del tribunal en el proceso es evidente. Para que la inmediación tenga pleno vigor, el juez debe asumir en la audiencia un rol de director, actuando con mesura y razonabilidad, cuidando en todo momento su imparcialidad. Sus condiciones personales resultan de mucha mayor trascendencia que en un proceso donde no rige la inmediación. Debe conocer las técnicas de negociación y conciliación que se han desarrollado en relación al proceso por audiencias, y sentirse humilde protagonista de una labor fundamental para la sociedad, que requiere de grandes esfuerzos. La inmediación significa sacrificio no solo para los jueces, sino también para los abogados, porque exige un conocimiento completo y constante del asunto controvertido. La inmediación requiere mutua colaboración entre los abogados y para con el juez, en esa obra en común que es cada audiencia y el proceso todo. Sin esta interacción esencial fundada en la buena fe, la inmediación deja de ser tal”. PEREIRA (2003) p. 3.

${ }^{104}$ Ya se han alzado voces críticas al modelo de juez que se recogió a propósito de la reforma procesal laboral: “... el nuevo procedimiento laboral no respeta ni siquiera el estándar mínimo del principio dispositivo”. PALAVECINO (2009) p. 82.

105 Nemo iudex sine actore, reza el conocido aforismo subrayando que el proceso no tendrá inicio si no hay un actor que inste por el proceso. Acudirá o no al proceso para la defensa de sus derechos e intereses atendiendo a razones de oportunidad (principio de oportunidad). Existe libre poder de disposición, de allí la posibilidad de renuncia o desistimiento. El fundamento constitucional de este principio procesal debe buscarse en el art. $19 \mathrm{~N}^{\circ} 24,21$ y 23 de nuestra Carta Fundamental.

106 También consecuencia de la vigencia del principio dispositivo. El objeto del proceso queda configurado según sea lo que quiera hacer valer el actor y lo que quiera hacer valer el sujeto pasivo. La determinación del objeto del proceso es facultad exclusiva de las partes. Por lo mismo, la sentencia debe guardar una congruencia con las pretensiones formuladas por las partes: El juez no puede conceder más de lo pedido, 
dos del proceso, los que dependen en importante medida del adecuado ejercicio por los litigantes de las distintas oportunidades de actuación procesal previstas por la ley, muy especialmente lo que liga con la aportación al proceso de los elementos fácticos y la prueba de los hechos que les interesen. Otra postura poseen aquellos que asocian la oralidad como producto de la corriente publicizadora del proceso civil ${ }^{107}$.

Concretamente, si bien es cierto que en el marco de un proceso civil oral debe revalorizarse la importante figura del juez, ello no debe implicar tener que gravar a los tribunales con cargas que no debieran asumir. La proposición, obtención y producción de las pruebas es (y debe ser) fundamentalmente tarea de las partes. La tarea del tribunal debe pasar por presenciar efectivamente la rendición de las pruebas y las alegaciones de las partes, pero debiera abstenerse de intervenir en apoyo de una u otra pretensión, so pena de arriesgar su imparcialidad y el debido respeto a la igualdad de armas de las partes ${ }^{108}$. Sin perjuicio, obviamente, de que le corresponderá valorar la prueba producida.

No es razonable ni conveniente que al tribunal le corresponda sustituir la labor de las partes a través de la investigación y comprobación oficiosa de la veracidad de los hechos. No es entendible que por un lado se hayan disminuido los poderes del juez penal, en resguardo de su imparcialidad procesal y de las garantías de las partes (derecho de defensa entre otros), y por este otro se busque aumentar los poderes del juez dentro de un proceso civil. No es prudente ni realista que algunos sigan pensando este tema como si cada juez tuviera un proceso y cada abogado un caso ${ }^{109}$.

ni tampoco pronunciarse sobre algo no solicitado, ni fundamentarse en hechos y argumentos jurídicos que las partes no hayan querido aducir. Véase lo dispuesto en los arts. $170 \mathrm{~N}^{\circ} 6$ y $768 \mathrm{~N}^{\circ} 4$ del CPC.

107 Para consulta, entre otros, véase: PICÓ (1998): "La iniciativa probatoria del juez civil y sus límites". Revista del Poder Judicial, N 51, III: pp. 270 y ss.; TARUfFO, M. (2003): "Investigación judicial y producción de prueba por las partes". Revista de Derecho, Universidad Austral de Valdivia, vol. XV: pp. 205-213; PICÓ, J.; ABEL, X. (2003): Los poderes del juez civil en materia probatoria (Barcelona, Ed. Bosch); Etxeberría, J. (2003): Las facultades judiciales en materia probatoria en la LEC (Valencia, Ed. Tirant Monografías); Cappelletti, M. (1974): Proceso, ideologías y sociedad (Buenos Aires, Ejea, traducción de Santiago Sentís), pp. 22 y ss.; BAUR, F. (1973): “Liberalización y socialización del proceso civil”. Revista Iberoamericana de Derecho Procesal, N²-3; Devis ECHANDÍA, H. (1967): "La iniciativa probatoria del juez civil en el proceso contemporáneo". Revista de Derecho Procesal Iberoamericana, N IV.

108 Alvarado (2008) pp. 149-164.

109 Que "las partes no son iguales" y "no pueden acceder a abogados de igual calidad y preparación”; que "la parte con mayores recursos económicos accede a mejores abogados”, se sentencia. Pues bien, frente a estas afirmaciones se puede señalar, al menos, lo siguiente. Primero, como bien ha recordado Maturana, la Justicia civil no puede poner remedio a todas las formas de injusticia o a todos los males existentes en la sociedad: la tarea de poner remedio a los problemas sociales corresponde realmente a otros órganos, legislativos o de gobierno. No se puede pretender solucionar el problema de la desigualdad con leyes procesales. Segundo, no necesariamente el abogado del Estudio más grande e importante es mejor abogado. Y aun no siendo así, se olvida, además, que en la realidad los litigios que involucran mayores sumas de dinero reúnen justamente a abogados de Estudios más importantes, mientras que en los casos menores, sin tanta importancia económica, no aparecen estos abogados de grandes Estudios (Montero). Y tercero: imaginemos (nos invita De la Oliva) que el Estado asume el costo de los abogados y garantiza a todos acceso a uno (en otras palabras, que el Estado expropia la profesión legal). Cabe preguntarse si ¿serán todos estos abogados estatales igualmente competentes? Naturalmente que la respuesta - dice De la Oliva- es negativa, habrán unos más competentes que otros, a menos que se esté pensando por alguno con mentalidad futurista en la clonación de un abogado competente. 
Pues bien, en cuanto a la adopción de mayores poderes oficiosos (materiales) por el juez, el Proyecto chileno es favorable a ella, ya desde el inicio del trayecto procesal, al permitirse al juez rechazar in limine la demanda cuando fuere manifiestamente infundada (entre otras hipótesis). En efecto, sin tramitar proceso alguno, el juez estará facultado para desechar de entrada determinadas demandas, cuestión que desde luego puede generar tensión desde el punto de vista constitucional, específicamente en relación a una eventual incompatibilidad con el derecho a un debido proceso, mecanismo establecido para la resolución de los conflictos. Somos críticos de esta facultad, pues consideramos que puede dar lugar a actuaciones arbitrarias que, lejos de atender a los objetivos perseguidos con la norma, terminen por coartar tempranamente legítimas demandas.

En materia de actuación probatoria de oficio, en el modelo actual los poderes se traducen básicamente en las medidas para mejor resolver. En el PCPC desaparecen estas medidas para mejor resolver: El PCPC opta por su eliminación ${ }^{110}$. Esta supresión podría leerse como una decisión de respetar con mayor coherencia y firmeza el principio de aportación de partes garantizando el deber de imparcialidad del tribunal y la igualdad procesal que se consagran. Pero la verdad es que esta eliminación, unida a la lectura de otras normas que se proponen, debiera leerse como el propósito de intentar que la actividad oficiosa del tribunal en materia de prueba no quede relegada para el final del trayecto procesal como ocurre hoy en día. En primer lugar, el art. 18 No 4 consagra dentro de las facultades del tribunal la ordenación de las diligencias necesarias para el esclareciendo de la verdad de los hechos controvertidos, respetando el derecho de defensa de las partes (¿cómo?), en la oportunidad establecida en la ley (¡cuál?). De otro lado, el art. 304 dispone que la prueba se rendirá de acuerdo al orden que fijen las partes, comenzando por la del actor y al final se rendirá la que pudiere ordenar el juez.

La regulación contenida en el PCPC toma una opción hacia el aumento de los poderes oficiosos del juez civil. La pregunta es si pasa por esa medida la solución a los problemas de esta Justicia, o si junto con solucionar nada, estaremos incorporando elementos que afecten los principios de todo proceso, así como la adecuada distribución de cargas a los distintos actores de un proceso civil.

\section{CONCLUSIONES FINALES}

De lo expuesto pueden deducirse una serie de consideraciones conclusivas generales (sin perjuicio de las observaciones más particulares realizadas en el cuerpo de este trabajo) que buscan destacar las pautas que debe seguirse en la discusión de la reforma procesal civil en los ámbitos que han sido objeto de este estudio.

\footnotetext{
${ }^{110}$ La eliminación de estas medidas para mejor resolver de nuestro modelo procesal civil sería una solución, en principio, más ajustada a un proceso oral y concentrado que refuerza la importancia del acto del juicio. Su existencia, se ha dicho, no tendría justificación dentro de lo que debe ser una adecuada mecánica procesal, puesto que terminado el juicio el juez no debiera tener en cuenta hechos nuevos, ocurridos con posterioridad a la terminación, o que se hayan conocido con posterioridad a esta terminación. Sin embargo, bien vale la pena analizar más profundamente la eliminación del instituto (pensando más en su reformulación que en su eliminación, como se hizo en la LEC española) porque pudiera resultar necesario y útil en algunos casos.
} 
1) Está probado que un modelo procesal civil oral permite una mejora en la calidad de la Justicia, pues las exigencias de la inmediación y la concentración -asociadas a la oralidad- posibilitan una mayor cercanía del juez con la materia que ha de ser juzgada por él. El modelo que se propone en el PCPC recoge adecuadamente estas bases cuya interrelación deben permitir una Justicia de mayor calidad. Como bien se ha destacado, un sistema judicial es eficiente cuando se orienta estructuralmente para llegar a decisiones informadas, precisas y responsables ${ }^{111}$.

Empleando palabras de Pereira, un destacado procesalista uruguayo, se busca consagrar en nuestro país una estructura hoy consolidada como la más adecuada, que es el proceso "por audiencias". En efecto, el PCPC regula un sistema procesal en el que, luego de la demanda y contestación escritas, las partes y el juez se reúnen. En audiencia, frente a frente, los litigantes y sus abogados, con la presencia e intervención activa del juez como director, se trata de llegar prioritariamente a una conciliación total o parcial y, en su defecto, se realiza el debate y se fijan los puntos en disputa de manera clara y concreta. Se hacen efectivos así los principios procesales fundamentales y, especialmente, se garantiza la inmediación. Se trata de un proceso que deben realizar efectivamente y en su conjunto, sus tres principales sujetos (las partes y el juez), obteniendo así un efectivo acercamiento a la realidad concreta que forma el objeto sustantivo del proceso, concentrándose sus actuaciones. La sede del tribunal deja de ser el lugar en donde se presentan y se intercambian escritos para formar el expediente y se transforma en el lugar donde se hace el proceso con la presencia de sus protagonistas esenciales ${ }^{112}$.

2) Otra de las conclusiones que se extraen es que para alcanzar este salto cualitativo no es necesario ni conveniente que absolutamente todas las actuaciones del proceso sean orales: sin perjuicio de lo apuntado respecto de la audiencia preliminar, la oralidad debe reservarse en todo caso para la práctica de las pruebas, esto es, para el acto del juicio en sí, ya que es este el momento en que el tribunal ha de tomar un contacto más directo con los hechos en que las partes sostienen sus pretensiones. Sin embargo, puede seguir siendo razonable que las alegaciones de las partes se realicen por escrito, siempre que queden sujetas a plazos razonables, pero en todo caso preclusivos. Debe valorarse positivamente que se haya esquivado fórmulas más simplistas que quisieren que ya la contestación fuere oral: el predominio de la oralidad en el proceso civil no impide ni puede impedir -razonablemente- recurrir a la forma escrita, al menos cada vez que sea necesario para el mejor desempeño de los objetivos de cada fase y acto procesal ${ }^{113}$. En el Proyecto la oralidad aumenta y se refuerza, es la forma predominante, pero no ha sido por la asunción de alguna moda o por imponerlo así cierta visión doctrinaria e ideológica de lo que debe ser la modernidad procesal. En el Proyecto la oralidad aumenta teniendo a la vista un criterio que liga con la funcionalidad de cada etapa del proceso.

\footnotetext{
111 TARUFFO (2008).

112 PEREIRA (2003).

113 Seguramente se han tenido a la vista las modificaciones introducidas a la apuesta original en la reforma de la Justicia de familia y laboral.
} 
A partir de la opción no fanática hacia un fortalecimiento de la oralidad, la concentración y la inmediación, se debe avanzar hacia un nuevo y mejor modelo. Este modelo debe aprovecharse de las marcas que se derivan de esta apuesta formal (especialmente en lo que dice relación con la mayor posibilidad de obtener una respuesta jurisdiccional de mejor calidad y en un tiempo más razonable, por lo tanto una respuesta jurisdiccional más eficiente), y debe evitar caer en excesos (puramente doctrinarios, poco conscientes de la realidad). Los cambios propuestos en cuanto al sistema probatorio parecen razonables, sin perjuicio de la observación realizada sobre la conveniencia de ser más explícitos y claros con las reglas de valoración legal que se consagrarán (prueba documental, entre otras).

3) Parece sensato que no tiene especial sentido que los procesos civiles, una vez formuladas por escrito las alegaciones de las partes, comiencen directamente con un juicio oral en que se practiquen sin más las pruebas: al contrario, la experiencia demuestra que los juicios orales solo son efectivos si les ha precedido una labor previa de preparación de ese juicio. De entrada, porque solo tiene sentido llegar al juicio si ya se ha verificado que a su término el tribunal podrá dictar una sentencia sobre el fondo, esto es, una vez que se ha comprobado que no concurren defectos procesales o que se han subsanado los concurrentes. Y, por otra parte, el desarrollo del juicio solo será eficaz si desde su inicio todos sus protagonistas - esto es, litigantes y juez- tienen claro de antemano cuál es el objeto del proceso, cuáles son los hechos controvertidos y cuáles son las pruebas de que va a servirse cada cual. Desde este segundo punto de vista, la adecuada preparación del juicio garantiza el derecho de defensa, en la medida en que evita sorpresas a los litigantes, inevitables cuando no se han determinado con antelación ni el thema decidendi ni el thema probandi.

4) Se debe entender que no se pueden construir los procesos en abstracto, en la ley, como si se pensase que cada juez y cada abogado tienen solo uno. Es necesario aprovechar de algún modo que esta reforma llega con muchos años de retraso si se mira la evolución de la instauración de los procesos orales en el mundo. Es necesario sacar provecho de la experiencia acumulada tanto fuera como dentro de nuestro país en materia de procesos orales. El análisis del articulado del PCPC nos muestra que falta bastante en la mejor regulación de algunas materias, en algunos casos es de más sencilla solución (plazo para dictar sentencia en el juicio ordinario, que aparece como insuficiente), en otros de más complejo acuerdo como por ejemplo en la definición del papel del juez en materia probatoria. De hecho, existen en varias de las normas propuestas el germen de la configuración de un juez civil que poco tiene que ver con un proceso civil gobernado por los principios dispositivo y de aportación de parte. En este punto más que atender a referentes comparados, conviene afinar una propuesta que finalmente sea coherente con el debido proceso y con la realidad de nuestra judicatura.

Es esencial que en las etapas que siguen en este proceso de reforma se tenga perfectamente claro que no basta con el diseño de modelos procesales abstractos que resulten perfectos a la luz de las exigencias de la doctrina, sino que, con más pragmatis- 
mo y realismo, se deben dirigir los esfuerzos a la consecución de un mejor modelo que sea practicable.

5) Por fin, para que un diseño procedimental razonable puede llevarse a la práctica en forma adecuada, no puede obviarse la necesidad de poner a disposición de la Reforma los recursos humanos y materiales que se requiera para llevar adelante las mayores exigencias de una Justicia que ya no será "de Potreros". No entender este punto puede hacer que se reproduzcan en sede procesal civil los problemas ya experimentados en materia de Justicia de familia, por ejemplo, la sistemática infracción de los plazos procesales en el señalamiento de las actuaciones orales, que hace que lo dispuesto por el legislador transite por un camino muy diverso al que la praxis viene mostrando, aun tras las reformas realizadas a la citada reforma. No se trata de que nuestros jueces no hagan bien su trabajo (al menos esta no será la regla), sino que la sistemática infracción de los plazos muchas veces liga con la imposibilidad física de cumplir con dichos plazos legales. Se va generando un peligroso escenario: o bien se infringen los plazos que se han previsto en la ley para el señalamiento de las audiencias que comprenden los procesos orales, o por los jueces se trata de cortar la duración de cada una de las audiencias, limitando de paso los derechos de los intervinientes y sacrificando las verdaderas ventajas que aporta la oralidad-inmediación haciendo de todo un simulacro de oralidad poco útil y costoso. Bien lo ha apuntado Picó ${ }^{114}$, hay que poner atención a los síntomas de "fatiga" de la oralidad en los juicios, lo que requiere, de un lado, un mayor control del trabajo diario de los tribunales, y del otro, si es posible, un incremento del número de juzgados para "ajustar la realidad a la legalidad".

\section{BIBLIOGRAFÍA UTILIZADA}

ABEL, Xavier (2003) "La audiencia previa: entre el deseo y la realidad". Revista del Poder Judicial, $\mathrm{N}^{\circ}$ 69: pp. 335-372.

Alonso-Cuevillas, Jaime (2000): Instituciones del nuevo proceso civil. Comentarios sistemáticos a la Ley 1/2000. (Barcelona, Ed. Difusión Jurídica, volumen II).

Alvarado, Adolfo (2008): "Imparzialità del giudice e Giusto processo" en: CiPRIANI, F. Stato di diritto e garanzie processuali (Napoli, Edizione Scientifiche italiane, Quaderni de Il giusto processo civile, 2).

ANDRES, Perfecto (2003): "Sobre el valor de la inmediación (Una aproximación crítica)”, Revista Jueces para la Democracia 46: pp. 57-66.

BONET, José (2008) "El proceso civil español como modelo procesal de oralidad", Revista de Derecho Procesal de la Universidad de Chile, No 21: pp. 151-172.

CAPPELletTI, Mauro (1971): Procédure orale et procedure écrite (Milán-Nueva York, Giuffrè) 116 pp.

114 PICÓ (2008). Este autor apunta que la infracción judicial de los plazos legales es aún asumible en España, pero que se requiere tomar medidas desde ya para evitar que estos síntomas de fatiga de la oralidad se reproduzcan y expandan. 
Cappelletti, Mauro (1972): Proceso oral y proceso escrito (Buenos Aires, Ed. Ejea, traducción de Sentís Melendo).

CAPPELletTi, Mauro (1974): Valor actual del principio de oralidad. La oralidad de las pruebas en el proceso civil (Buenos Aires, Ed. Ejea, traducción de Sentís Melendo y Thomás A. Banzhaf).

CARocca PÉrez, Alex (2003): Manual de Derecho procesal: Los procesos declarativos (Santiago, Ed. LexisNexis) tomo II.

CARreraS, Jorge (1962): “El Derecho procesal como arte”, en: CARRERAS, Jorge y FENECH, Miguel, Estudios de Derecho procesal (Barcelona).

CARús, Jefferson (2003): O princípio da oralidade. Procedimento por audiencias no Directo Processual Civil Brasileño (São Paulo, Ed. Revista dos Tribunais, Colecao Estudos de Directo de Processo) vol. 53.

Chiovenda, Giuseppe (1924): "L`oralità e la prova" Rivista di Diritto Processuale Civile, vol. I.

CruZ, Sergio (2008): "La oralidad en la Justicia. El caso brasileño", Revista Ius et Praxis, año 14, vol. II: pp. 127-145.

DAMASKA, Mirjan (2000): Las caras de la Justicia y el poder del Estado. Análisis comparado del proceso legal (Santiago, Ed. Jurídica de Chile, traducción de Andrea Morales Vidal) $452 \mathrm{pp}$.

De la Oliva (1999) "Panorama general de la nueva Ley de Enjuiciamiento Civil y criterios inspiradores", Revista de Derecho Procesal, No 2: pp. 359-394.

De la Oliva, Andrés y DíEZ-PICAZO, Ignacio (2004): Derecho procesal civil. El proceso de declaración (Madrid, Ed. Universitaria Ramón Areces, 3a edición) 684 pp.

De la Oliva, Andrés, Díez-Picazo, Ignacio y VegAS, Jaime (2004): Derecho procesal: Introducción (Madrid, Ed. Universitaria Ramón Areces, 3a edición) 456 pp.

De la Oliva Santos, Andrés y Palomo Vélez, Diego (2007): Proceso civil: Hacia una nueva Justicia civil (Santiago, Ed. Jurídica de Chile) 700 pp.

De la Oliva, Andrés (2008): Casación, oralidad y nuevo proceso civil (tres conferencias chilenas). (Santiago, Ed. Jurídicas de Santiago) 93 pp.

DEVIS, Hernando (1972): "Cientificidad de la prueba, en relación principalmente con los dictámenes periciales y la libertad de apreciación del juzgador", Revista de Derecho Procesal Iberoamericana, No 1.

Duce, Mauricio, Marín, Felipe, y Riego, Cristián (2008): "Reforma a los procesos civiles orales: consideraciones desde el debido proceso y calidad de la información”, en: Cabezón, A. (Coord.). (2008) Justicia Civil: Perspectivas para una reforma en América Latina (Santiago, CEJA). Disponible en: <http://www.cejamericas.org/doc/proyectos/ Justiciacivil2008_ceja.pdf> [fecha de consulta: 13 de noviembre] pp. 13-94.

GASCÓN, Fernando (2008): "Un nuevo instrumento para la tutela de los consumidores y de los créditos transfronterizos: el proceso europeo de escasa cuantía”, Revista Ius et Praxis, vol. 14 No 1: pp. 167-197.

GASCÓn, Fernando y PALOMO, Diego (2007): "La audiencia previa al juicio en el modelo procesal civil español”, Revista Hispano-Chilena de Derecho Procesal Civil, ${ }^{\circ}$ 1: pp. 51-121. 
Gimeno, Vicente (2007): "Análisis crítico de la Ley de Enjuicimiento Civil”, Revista Justicia, No 116: pp. 237-256.

Gutiérrez, V. y Maldonado, F. (2006): Diagnóstico de la actual Judicatura Civil: Percepción social y análisis de trayectorias de causas (Santiago, Proyecto Reforma procesal civil de la Sociedad para la cooperación técnica alemana GTZ-Chile).

Informe de Foro para la reforma procesal civil (2008): Revista de Derecho Procesal de la Universidad de Chile, No 21.

Instituto Iberoamericano de Derecho Procesal (1994): El Código Procesal Civil Modelo para Iberoamérica (Caracas, Academia de Ciencias Políticas y Sociales).

MARTín, Fernando (2008): "Oralidad y eficiencia del proceso civil: ayer, hoy y mañana”, ponencia realizada en Coloquio Internacional de la Asociación Internacional de Derecho Procesal Oralidad y escritura en un proceso civil eficiente, realizado en Gandía (España) en los días 6, 7 y 8 de noviembre del presente año. Disponible en: <http:// www.uv.es/coloquio/coloquio/comunicaciones/pi2mar.pdf $>$ [fecha de consulta: 13 de noviembre].

MATURANA, Cristián (2002): "Un moderno sistema probatorio para el proceso civil", Revista del Colegio de Abogados de Chile, No 24.

MEneses, Claudio (2008): "Fuentes de prueba y medios de prueba en el proceso civil", Revista Ius et Praxis, vol. 14 No 2: pp. 43-86.

Montero, Juan (2001): Los principios politicos de la nueva Ley de Enjuiciamiento Civil: Los poderes del juez y la oralidad (Valencia, Ed. Tirant lo Blanch) 190 pp.

Montero, Juan (2006): Proceso civil e ideología (Valencia, Ed. Tirant lo Blanch) 451 pp.

MONTERO, Juan (2008): "Valoración de la prueba, reglas legales, garantía y libertad en el proceso civil”, en: CIPRIANI, Francesco, Stato di diritto e garanzie processuali (Napoli, Edizione Scientifiche italiane, Quaderni de Il giusto processo civile, 2).

NiEVA, Jordi (2007): "Los problemas de la oralidad", Revista Justicia, No 1-2: pp. 101130.

NúÑEZ OJEDA, Raúl (2005): "Crónica sobre la reforma del sistema procesal civil chileno (fundamentos, historia y principios)", Revista de Estudios de la Justicia, N6: pp. 175-190.

PALAVECINO, Claudio (2009): “El retorno del inquisidor. Las potestades judiciales en materia probatoria en el procedimiento laboral chileno", Revista Laboral Chilena, No 173: pp. 73-85.

PAlOMO, Diego (2007): "Nuevo proceso civil español: sobre algunas de las más positivas consecuencias de la apuesta por un modelo oral, concentrado y sin intermediarios", Revista de Derecho de la Universidad Católica del Norte, No 1: pp. 131- 210.

PAlomo, Diego (2008): Oralidad en el proceso civil. El nuevo modelo procesal civil español (Santiago, Ed. Librotecnia) 690 pp.

PEREIRA, Santaigo (2003): "El principio de inmediación en el proceso por audiencias: mecanismos legales para garantizar su efectividad. El Código General del Proceso Uruguayo y el Código Procesal Civil Modelo para Iberoamérica”. Revista Internauta de Práctica Jurídica - Semestral de Dret Processual i Práctic, Facultad de Derecho de 
la Universidad de Valencia, No 11: Disponible en: http://www.uv.es/ ripj/ 11 sant.htm [fecha de consulta: 13 de noviembre de 2008].

PereirA, Santiago (2005) "Oralización de los procesos civiles en Uruguay: la exitosa aplicación desde hace 15 años del CPC Modelo para Iberoamérica” (Ponencia en Seminario Interamericano Claves para una reforma a la Justicia Civil organizado por CEJA, en Santiago, entre el 10 y 11 de noviembre de 2005).

PEREIRA, Santiago (2008): El proceso civil ordinario por audiencias. La experiencia uruguaya en la reforma procesal civil. Modelo teórico y relevamiento empírico (Montevideo, Editorial Amalio Fernández) 134 pp.

PereirA, Santiago (2008): "La reforma de la Justicia civil en Uruguay. Los procesos ordinarios civiles por audiencias", en: CABEZÓN, A. (coord.), Justicia civil: Perspectivas para una reforma en América Latina. (Santiago, CEJA). Disponible en: <http:// www.cejamericas.org/doc/proyectos/Justiciacivil2008_ceja.pdf> [fecha de consulta: 13 de noviembre de 2008].

Pérez-Ragone, Álvaro y Ortiz, Juan Carlos (2006): Código Procesal Civil alemán (ZPO). Traducción con un estudio introductoria al proceso civil alemán contemporáneo (Montevideo, Fundación Konrad Adenauer, Programa Estado de Derecho para Sudamérica) $501 \mathrm{pp}$.

PICÓ, Joan (2008): “El principio de oralidad en el proceso civil español”, ponencia realizada en Coloquio Internacional de la Asociación Internacional de Derecho Procesal Oralidad y escritura en un proceso civil eficiente, realizado en Gandía (España) en los días 6, 7 y 8 de noviembre del presente año. Disponible en: <http://www.uv.es/ coloquio/coloquio/Ponenc.htm> [fecha de consulta: 13 de noviembre de 2008].

RAmos, F. (2008) "Forma del proceso y funcionamiento de la Justicia: Análisis de Derecho Comparado. Ponencia realizada en Coloquio Internacional de la Asociación Internacional de Derecho Procesal Oralidad y escritura en un proceso civil eficiente, realizado en Gandía (España) en los días 6, 7 y 8 de noviembre de 2008. Disponible en: <http://www.uv.es/coloquio/coloquio/Ponenc.htm> [fecha de consulta: 13 de noviembre de 2008].

SChipiani, S. y VACCARElla, R. (Coord.). (1988) Un “Codice Tipo" di procedura civile per L'America Latina. (Padova, CEDAM, Memoria del Congreso Internacional realizado en Roma 26/28 septiembre de 1988).

SENTÍs, Santiago (1978): La prueba, los grandes temas del derecho probatorio (Buenos Aires, Ejea) 608 pp.

Silva, J.; BAeZA, G.; GonZÁlez, P. y LecAros, B. (2008): "Estudio exploratorio sobre el funcionamiento de la oralidad en los Tribunales de Familia en la Región Metropolitana”, en: Cabezón, A. (coord.), Justicia civil: Perspectivas para una reforma en América Latina. (Santiago, CEJA). Disponible en: http://www.cejamericas.org/doc/proyectos/Justiciacivil2008_ceja.pdf

STEIN, Friedrich (1973): El conocimiento privado del juez (Pamplona, Ed. Areces, traducción de Andrés de la Oliva) 238 pp.

STORME, M. (2008): "Más voz y menos letra: en defensa de la oralidad en los procesos civiles", ponencia realizada en Coloquio Internacional de la Asociación Internacional 
de Derecho Procesal Oralidad y escritura en un proceso civil eficiente, realizado en Gandía (España) en los días 6, 7 y 8 de noviembre de 2008. Disponible en: <http:// www.uv.es/coloquio/coloquio/Ponenc.htm> [fecha de consulta: 13 de noviembre].

TARUfFo, Michele (2008): "Oralidad y escritura como factores de eficiencia en el proceso civil", ponencia realizada en Coloquio Internacional de la Asociación Internacional de Derecho Procesal Oralidad y escritura en un proceso civil eficiente, realizado en Gandía (España) en los días 6, 7 y 8 de noviembre de 2008. Disponible en: <http://www.uv.es/coloquio/coloquio/Ponenc.htm> [fecha de consulta: 13 de noviembre de 2008].

VARGAS, J. (ed.). (2007): Nueva Justicia civil para Latinoamérica: aportes para la reforma. (Santiago, CEJA). Disponible en: <http://www.cejamericas.org/cejacommunity/ ?id=180> [fecha de consulta: 13 de noviembre de 2008].

VilladiegO, C. (2008): "Avance en América Latina y el Caribe de la reforma a la Justicia civil", en: Cabezón, A. (coord.), Justicia civil: Perspectivas para una reforma en América Latina. (Santiago, CEJA). Disponible en: <http://www.cejamericas.org/doc/ proyectos/Justiciacivil2008_ceja.pdf> [fecha de consulta: 13 de noviembre de 2008]. 
